\title{
Lógica para Modelos de Integração de conhecimentos para auxílio à decisão - plantios florestais ecológico-econômicos em zonas de recarga de aqüíferos
}

\author{
Paulo Pereira Martins Junior ${ }^{1,2}$, João Álvaro Carneiro', Issamu Endo ${ }^{3}$, \\ António Francisco Sá e Melo Marques', Vitor Vieira Vasconcelos 4 , Leandro Arb d'Abreu Novaes ${ }^{2}$, \\ Lawrence de Andrade Magalhães Gomes ${ }^{2}$ \& Douglas Rezende Jano ${ }^{5}$
}

\begin{abstract}
Resumo As Geociências Agrárias e Ambientais (GAA) integram ciências e conhecimentos para as práticas da agricultura, silvicultura e zoocultura na gestão agrogeológica e ambiental. Interligar ciências perfaz um conjunto de operações para constituir as: (1) bases de conhecimentos (2) articulações lógicas entre essas bases (3) e entre os modelos dos processos naturais e tecnológicos e (4) previsões de impactos que advenham a Zonas de Recarga de Aqüíferos (ZRAs), à circulação hídrica, a qualidade da água e a estabilidade dos terrenos. Para o ato de decidir, a questão central é internalizar nos procedimentos lógicos "os aspectos de corte para a decisão" entre as diversas ciências, técnicas, sistemas naturais e temas de segurança. Quatro questões geo-ambientais estão no centro deste processo de auxílio à decisão para integrar as: (1) variáveis paramétricas medidas (2) condicionantes estruturais (3) condicionantes geodinâmicos e (4) sensibilidade a intervenções. Evidenciou-se passos lógicos para estabelecer um programa de auxílio à decisão que trate do conjunto de questões que envolvem esses temas para uso de áreas sensíveis como as ZRAs.
\end{abstract}

Palavras-chave: lógica interdisciplinar, decisão, recarga de aqüíferos, Geociências Agrárias e Ambientais, lógica para inteligência artificial, sustentabilidade.

\begin{abstract}
Logic Models for Integration of Knowledge to Aid Decision - Ecologic and Economic Forest Plantations in Areas of Aquifer Recharge. The Agrarian and Environmental Geosciences imply the integration of several sciences and fields of knowledge in order to assist farming, forestry and animals' bringing. To integrate those sciences and knowledge into a model it is necessary to bring conservation practices not only to the agronomical practices but at the same time into geo-ecological administration of watersheds. The interconnection of those sciences demands the organization of: (1) knowledge bases (2) a logical articulation system for these cognitive bases (3) logic models of natural processes and technology and (4) a prevision and control system of eventual anthropic-derived impacts in underground water recharge zones, water circulation, water quality and terrain stability. For the act of decision the central challenge is the internalization of "the cross-cutting aspects of decision" derived from the various sciences, natural systems and security issues. Four geo-environmental questions are central to the whole process of decision making, for the proper integration of practical knowledge, which involves the determination of the: (1) adequate parameters, (2) structural conditioning factors, (3) geodynamic factors, and (4) terrain/ecosystems susceptibility to anthropic interventions. The logical steps become thus evident for the design of decision making supporting systems, which will deal with themes involving sensible areas in watershed.
\end{abstract}

Keywords: interdisciplinary logic, decision, aquifers recharge, Agrarian and Environmental Geosciences, logic for artificial intelligence, sustainability.

INTRODUÇÃO A Lógica é o conhecimento que permite estabelecer regras de geração de conhecimentos. É universal para todo tipo de conhecimentos, mas apresenta algumas particularidades em função das ciências e dos sistemas que estejam sendo tratados. Tem-se como finalidade tratar da questão da Lógica Interdisciplinar para se vir estabelecer programas de auxílio à decisão com apoio das técnicas de inteligência artificial ou computacional (Ginsberg 1993) para a implantação de corredores florestais.

Para uma modelagem interdisciplinar é necessário desenvolver-se o que se denomina uma "arquitetura de conhecimentos", tema complexo, mas simplificador para o usuário. Define-se como: "um sistema que integra conhecimentos universais, fundamentais e particu-

1 - UFOP-EM-DEGEO, Ouro Preto (MG) e Fundação CETEC, Belo Horizonte (MG), Brasil. E-mails: maerteyn@gmail.com, paulo.martins@cetec.br

2 - Fundação CETEC, Belo Horizonte (MG), Brasil. E-mail: alvaro.carneiro@cetec.br, francisco.melo@cetec.br, leandroarb@yahoo.com.br, lawrence_amg@yahoo.com.br, 00vinicius@gmail.com

3 - UFOP-EM-DEGEO, Ouro Preto (MG), Brasil. E-mail: issamu@degeo.ufop.br

4 - Fundação CETEC, Belo Horizonte (MG), Brasil, bolsista CNPq e FAPEMIG. E-mail: vitor.v.v@gmail.com

5 - PUC/CETEC, E-mail: dougjano@gmail.com 
lares de diversas ciências, coligados aos conhecimentos cartográficos necessários, e articulados a sistemas executáveis que permitam modelar relações quantitativas e qualitativas" (Martins Jr. et al. 2005-2008). Este tipo de sistema serve de base para os sistemas de auxílio à decisão. Desse modo, problemas geo-ambientais e agrários podem ser integrados em quadros de soluções. A arquitetura de conhecimentos é, neste caso, coordenada pelo tema Geo-ecologia e Economia.

Desde 1998, procura-se fundamentar o tema Geociências Agrárias e Ambientais (GAA) (Martins Jr. 1986, Martins Jr. et al. 2006, Carneiro 2006, Martins Jr. et al. 2008) que constitui um campo epistemológico necessário para integrações pluri- e inter- disciplinares.

As Zonas de Recarga de Aqüíferos (ZRAs) e as Áreas Precisas de Recarga (APRs) apontam para desafios de utilização dessas áreas sensíveis com projetos agrícolas, florestais, agro-florestais, de zoocultura e de industrialização rural. Este amplo quadro de questões envolve a decisão sobre o correto uso da terra para os vários tipos de reflorestamento. Para isso, deve-se considerar ciências e temas como: - Hidrogeologia - Hg, Engenharia florestal - EF, Pedologia -Pd, Aptidão de solos -AS, Segurança química - SQ, Modelagens hidrodinâmicas $\mathrm{MH}$, Geotecnia - Gt, Climatologia - Cl, Lito-estratigrafia - LE, Geologia estrutural - GE, Geomorfologia - Gm e Inteligência artificial - IA. Martins Jr. et al. (2006) trataram LE e GE de modo mais específico. Trata-se neste texto de EF, $\mathrm{Pd}, \mathrm{Cl}, \mathrm{Gm}, \mathrm{SQ}$ e AS para se progredir com a construção de um quadro lógico de auxílio à decisão.

Objetivos Busca-se integrar conhecimentos derivados das Geociências e de várias outras ciências, com especial ênfase na questão do uso agrícola e florestal das ZRAs e APRs, de modo a criar um campo epistemológico-metodológico interdisciplinar, próprio para o auxílio à decisão, sobre aspectos como "o que plantar", "onde plantar" e "como plantar" de modo viável geoecológico e econômico.

Problemas Enumeram-se alguns problemas de modo a centrá-los nos aspectos epistemológico / metodológicos: (1) necessidade lógica de articular e integrar diversos setores de conhecimentos desenvolvidos originariamente com maior, menor ou inexistente associação entre os mesmos, sendo este o problema principal, (2) desenvolver com algumas ciências, acima citadas, a lógica sistêmica que articule esses diversos conhecimentos com o desafio de implantar corredores florestais sobre grandes extensões, com grande variabilidade do substrato, e (3) mostrar que a lógica estabelecida é necessária para efetivar e programar um sistema de inteligência artificial.

ZONAS DE RECARGA E AGRICULTURA INTENSIVA No Brasil tem sido prática, independente da legislação vigente, plantar-se em ZRAs e APRs, até por não se saber de modo sistemático onde efetivamente elas se encontram, e quais os tipos geo-ambientais dessas áreas em cada bacia. A bacia do rio Paracatu (Fig. 1) é alvo de análise por ser ocupada por imen-

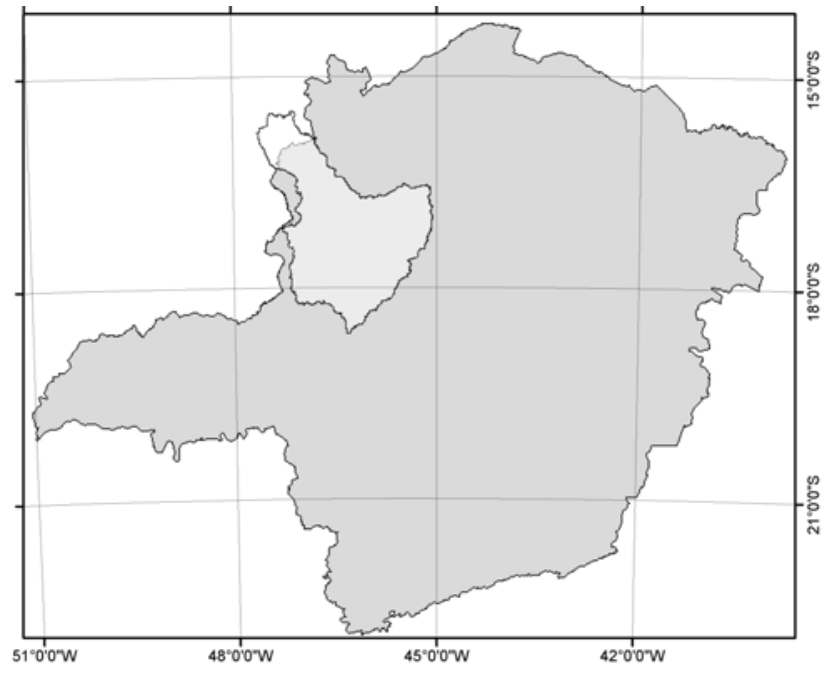

Figura 1 - Localização da bacia do Paracatu, nos Estados de Minas Gerais, Goiás e Distrito Federal, centro de um dos maiores pólos de agricultura intensiva irrigada do País com pivots de 100 a 600 ha (Org.: Martins Jr. 2007).

sos projetos de agricultura intensiva, com áreas intensamente irrigadas. Três aspectos centrais resumem as questões de uso das ZRAs e APRs: (1) localização, (2) caracterização geo-ambiental por tipos, e (3) localização em escala de detalhe das áreas precisas de recargas dentro de cada ZRA. Não se têm ainda respostas completas para esses três aspectos.

A tabela 1 apresenta algumas das relações fundamentais entre as questões centrais referentes aos usos citados de terras de ZRAS e APRs e as ciências especialistas.

\section{LÓGICA INTERDISCIPLINAR PARA AUXÍLIO À DECISÃO SOBRE O USO DA TERRA}

Inteligência artificial $O$ objetivo dos sistemas de Inteligência Artificial (IA) é de executar funções que sejam consideradas inteligentes. É um conceito amplo e recebe tantas definições quanto forem dados significados diferentes à palavra Inteligência. Dentre as características básicas ressalta-se a capacidade de replicar em certas medidas o raciocínio, isto é, aplicar regras lógicas a um conjunto de dados disponíveis, para chegar a uma conclusão. A "aprendizagem" (aprender com os erros e acertos de forma a no futuro agir de maneira mais eficaz), o "reconhecimento de padrões" (tanto visuais e sensoriais, como também padrões de comportamento) e a "inferência" (capacidade de conseguir aplicar o raciocínio nas situações de contexto humano) são partes das propriedades desses sistemas (Ginsberg 1993).

Sistemas Especialistas e Multi-Especialistas Sistemas especialistas são programas que têm como objetivo simular o raciocínio de profissional "expert" em um campo do conhecimento. Sistemas Multi-Especialistas são de tendência atual, visto que muitos problemas não são possíveis de se resolver com apenas um profissional especialista, mas necessita-se de equipes pluridisciplinares. Neste caso, o programa se torna especialista em 
Tabela 1 - Temas em relação com as ciências especialistas e com as questões centrais em relação ao uso de terras em ZRAs e APRs (Org.: Martins Jr. 2007).

\begin{tabular}{|c|c|c|c|c|c|c|c|c|}
\hline $\begin{array}{c}\begin{array}{c}\text { Ciências e } \\
\text { temas } \Rightarrow\end{array} \\
\text { Questões } \\
\text { centrais } 7\end{array}$ & $\begin{array}{c}\text { Lito- } \\
\text { estratigrafia }\end{array}$ & $\begin{array}{l}\text { Geologia } \\
\text { estrutural } \\
\text { e Geomor- } \\
\text { fologia }\end{array}$ & Pedologia & $\begin{array}{l}\text { Aptidão de } \\
\text { Solos }\end{array}$ & Geotecnia & Climatologia & $\begin{array}{c}\text { Modelagens } \\
\text { hidrodinâmicas }\end{array}$ & $\begin{array}{l}\text { Segurança } \\
\text { química }\end{array}$ \\
\hline $\begin{array}{c}\text { Localização } \\
\text { das ZRAs }\end{array}$ & $\begin{array}{l}\text { Estratos; } \\
\text { topografia; } \\
\text { petrografia }\end{array}$ & $\begin{array}{l}\text { estruturas } \\
\text { rúpteis e } \\
\text { dúcteis; } \\
\text { geoformas }\end{array}$ & tipos de solos & $\begin{array}{l}\text { tipos de } \\
\text { aptidão }\end{array}$ & \begin{tabular}{|c} 
atributos \\
físicos de \\
solos e/ou de \\
formações \\
superficiais
\end{tabular} & $\begin{array}{c}\text { estudo de } \\
\text { distribuição de } \\
\text { chuvas, } \\
\text { inundações e } \\
\text { fotoperiodi- } \\
\text { cidade; } \\
\text { cartas } \\
\text { agroclimato- } \\
\text { lógicas }\end{array}$ & \begin{tabular}{|c|} 
modelagens \\
de escoamento \\
superficial e da \\
infiltração
\end{tabular} & $\begin{array}{l}\text { porosidade; } \\
\text { limite de } \\
\text { liquidez; } \\
\text { permeabilidade }\end{array}$ \\
\hline $\begin{array}{l}\text { Localização } \\
\text { das APRs }\end{array}$ & $\begin{array}{l}\text { topografia, } \\
\text { petrografia }\end{array}$ & idem acima & tipos de solos & $\begin{array}{l}\text { tipos de } \\
\text { aptidão }\end{array}$ & $\begin{array}{l}\text { erosão } \\
\text { laminar, } \\
\text { erosão } \\
\text { profunda }\end{array}$ & $\begin{array}{l}\text { idem como } \\
\text { acima }\end{array}$ & $\begin{array}{l}\text { modelar } \\
\text { infiltração }\end{array}$ & $\begin{array}{l}\text { idem como } \\
\text { acima }\end{array}$ \\
\hline $\begin{array}{l}\text { Caracterização } \\
\text { geo-ambiental } \\
\text { por tipos de } \\
\text { ZRA e de APR }\end{array}$ & $\begin{array}{l}\text { intemperismo; } \\
\text { fraturas } \\
\text { abertas; } \\
\text { sedimentos; } \\
\text { solos }\end{array}$ & $\begin{array}{c}\text { geoformas; } \\
\text { declividades; } \\
\text { geo- } \\
\text { estruturas }\end{array}$ & $\begin{array}{l}\text { solos e } \\
\text { atributos } \\
\text { físicos }\end{array}$ & $\begin{array}{c}\text { tipos de } \\
\text { aptidão; } \\
\text { implicações } \\
\text { tecnológicas; } \\
\text { estudos de } \\
\text { viabilidade }\end{array}$ & \begin{tabular}{|c|} 
tipos de \\
solos e de \\
formações \\
superficiais; \\
erodibilidade
\end{tabular} & $\begin{array}{c}\text { intensidade } \\
\text { de chuvas; } \\
\text { direções de } \\
\text { impactos } \\
\text { das chuvas; } \\
\text { escoamento } \\
\text { superficial } \\
\text { local }\end{array}$ & \begin{tabular}{|c|} 
relação \\
infiltração \\
versus \\
escoamento \\
superficial pós- \\
chuvas
\end{tabular} & $\begin{array}{c}\text { famílias } \\
\text { de águas } \\
\text { subterrâneas } \\
\text { com potencial de } \\
\text { serem poluídas; } \\
\text { estudo de } \\
\text { poluição }\end{array}$ \\
\hline
\end{tabular}

dois ou mais ramos de setores científicos distintos, e usam-se esses conhecimentos de forma integrada para fornecer o melhor aconselhamento possível. Os sistemas multi-especialistas se mostram como promessas prementes nas GAA, Engenharias e Direito Ambiental sob enfoque interdisciplinar.

Questões agro-silvi-ambientais Colocam-se diversas questões sobre o uso das terras em ZRAs: (1) a estabilidade geotécnica, (2) alterações que possam advir quanto a manutenção da infiltração da água pluvial nos aqüíferos, e (3) infiltração de substâncias tóxicas para nos aqüíferos, tema da Segurança Química (Tab. 1). As ciências concernidas no campo epistemológicometodológico referentes às GAA dizem respeito a: (1) atributos geotécnicos dos solos, (2) aptidão dos solos para a agricultura determinada pelas condições - apto, restrito e inapto, (3) a Agroclimatologia que informa a compatibilidade da fenologia vegetal com as condições do clima, (4) a Hidrogeologia, (5) a Geologia Estrutural, que informa como estruturas dúcteis e rúpteis podem contribuir para a intercomunicação dos aqüíferos, (6) a Lito-estratigrafia, e (7) as Geomorfologia / Pedologia. Este é um quadro epistemológico-metodológico de ciências para o uso das ZRAs e APRs para fins agroflorestais e de zoocultura, como partes da cadeia produtiva de áreas agrícolas, de áreas para mitigação, de áreas de pastagens à industrialização rural.
Qualidade e avaliação da terra O conceito de "qualidade da terra" definido como "atributo complexo da terra, atuando como fator distinto para uso, em que cada qualidade da terra é determinada pela interação de um conjunto de características, com pesos diferentes, dependentes de todas as outras do conjunto, nos diferentes ambientes" (Beek 1978), é aqui adotado com a finalidade de englobar propriedades mensuráveis, sobre as quais os fatores de avaliação têm uma influência específica para o uso. Distinguem-se dois grupos de propriedades importantes para estimar o comportamento e potencialidade dos solos: (1) atributos que podem ser observados, medidos ou estimados quantitativamente no campo, ou em amostras de laboratório, e (2) atributos relativos ao seu comportamento, e que resultam de interações solo/ambiente, interpretáveis a partir de características observadas e/ou de resultados experimentais. Essa concepção de "qualidade da terra" (Lepsch et al. 1983) tem sido utilizada no Brasil, ainda que com algumas variantes, como idêntica a "condição do solo" ou também a "fator de limitação". Em todos os casos as "condições", "qualidades" ou "limitações" da terra sempre constituem uma ligação entre os recursos da terra inventariados e o planejamento do seu uso, mediante a identificação dos atributos que merecem ser observados, medidos e classificados. Assim, deverão sempre ser levados em conta os atributos essenciais para uso, sendo, por isso, tidos como determinantes "in- 
dependentes", com os seus efeitos previstos naqueles tidos como "dependentes". A qualidade da terra é crucial para a viabilidade da agro-silvicultura, mas podese apresentar não-viável em contraposição às condições geológicas de estabilidade ou de segurança ambiental em ZRAs, por não englobá-las de modo completo.

Existem claramente dois procedimentos básicos de classificação das terras em Agronomia, qualquer que seja o sistema, nas classes de utilização (Lepsch et al. 1983): (1) o Processo Paramétrico - no qual as características da terra, tidas como limitações, são devidamente hierarquizadas, e cada gleba ou geo-ambiente homogêneo é classificado com base na limitação mais severa que possuir, e (2) o Processo Sintético - no qual consideram-se as características da gleba como um todo, julgando suas limitações por comparação alternativa com as definições de classes de uso e/ou de aptidão.

Assim, a terra é enquadrada de acordo com a síntese dos graus das limitações que detém. Todavia, para Beek (1978, pág.78), e em contradição com a definição anterior, os métodos paramétricos são simplesmente os opostos do agora descrito, tratando-se de “... métodos que tentam incluir todos os fatores da terra que influenciam simultaneamente o desempenho do seu uso, utilizando uma análise quantitativa." Ou seja, constitui uma apreciação global, e portanto sintética, quantificada, desdobrando-se como regra nos seguintes passos: (1) avaliação independente das várias propriedades dos solos, atribuindo-lhes valores numéricos apropriados, (2) combinação dos fatores numéricos segundo uma expressão empírica, considerando suas relações e interações, para obtenção de um índice de desempenho e o qual destina-se a servir para o estabelecimento de valores relativos dos solos agricultáveis.

Contudo o Sistema FAO-Brasileiro (Ramalho Filho et al. 1983), embora baseado nos mesmos ditames, e seguindo várias das normas preconizadas por Beek (1978), utiliza para enquadramento das terras nas classes do sistema, o método paramétrico segundo definição de Lepsch (1983, pág.39). Ou seja, usa como limitante no enquadramento classificador o fator de limitação de grau mais severo ou restritivo.

As "qualidades da terra" listadas por Beek e Bennema (1972), no que dizem respeito ao desenvolvimento agro-florestal são: - disponibilidade de água, disponibilidade de nutrientes, disponibilidade de oxigênio na zona radicular, disponibilidade de espaço para desenvolvimento radicular, condições de germinação, salinização e/ou alcalinização, toxidez e acidez extrema, risco de inundação, doenças ligadas a condições edáficas, regime de temperatura, energia radiante e fotoperiodismo, ventos e tempestades, granizo e neve e geada, umidade do ar, períodos secos para maturação e colheita. Estas propriedades da terra são resultantes de atributos intrínsecos ou extrínsecos ao solo, tais como: (1) a disponibilidade de água é função não só do regime pluviométrico (2) como também da capacidade de retenção de água no solo, o qual por sua vez é resultante da granulometria, tipo de argilas e estruturas, entre outras características, (3) a disponibilidade de nutrientes, também designada por fertilidade, como função do complexo sortivo ou trocável, o qual é, por definição, a soma de bases de tro$\mathrm{ca}=\mathrm{S}$, capacidade de troca $=\mathrm{T}$, grau de saturação $=\mathrm{V}$, hidrogênio trocável $=\mathrm{H}$ e alumínio trocável $=\mathrm{Al}$, teores de fósforo assimilável, matéria orgânica, relação $\mathrm{C} / \mathrm{N}$, etc. Para quase todas as outras se aplicam raciocínios semelhantes, sendo raro que uma propriedade seja função exclusiva de uma só característica ou atributo.

Assim, torna-se muito difícil estabelecer, ou melhor, distinguir entre o que são condições, qualidades ou propriedades e atributos, ou características específicas da terra. Salienta-se que o conceito de "terra" é aqui bem mais amplo que o de solo, pois além deste, no strictu sensu compreende também as componentes ambientais que com ele interagem nos processos ecológicos e produtivos. Também por uma questão de critério optou-se por tomar como orientação o manual FAO-Brasileiro para listar as variáveis paramétricas a serem apreciadas, subordinando-se aos grandes fatores de limitação. Entre estes, três deles são considerados "ecológicos" ou naturais, sendo os dois restantes, tidos como "agrícolas". Os ecológicos, melhor dizendo ambientais, referem-se aos fatores de limitação: - (1) deficiências de fertilidade, (2) de água e (3) de oxigênio (excesso de água). Aqueles considerados agrícolas dizem respeito à (1) susceptibilidade a erosão e (2) impedimentos às práticas de mecanização.

Pode-se fazer o desdobramento dos "fatores de limitação" ou "propriedades" da terra, seguindo em linhas gerais, os critérios e normas preconizados em Ramalho Filho et al. (1983), segundo os atributos ou características que são determinantes para os fatores em referência. Podem igualmente designar-se por "variáveis paramétricas" (Tab. 2) na medida em que constituem referências para a avaliação do uso potencial da terra:

A - Deficiência de Fertilidade - Avaliada pela disponibilidade de suprimento de nutrientes e presença ou ausência de substâncias tóxicas; o respectivo índice é estabelecido através das seguintes características: (1) capacidade de troca de cátions (2) soma de bases trocáveis (3) saturação de bases (4) saturação com alumínio (5) salinidade e/ou alcalinidade (6) matéria orgânica (7) relação C/N (8) fósforo assimilável e (9) $\mathrm{pH}$.

B - Deficiência de Água - Avaliada pela extensão do período seco, em que existe déficit hídrico, isto é, aquele período em que a quantidade de água armazenada no solo é insuficiente para o completo abastecimento (evapotranspiração) da vegetação instalada; depende, como é evidente, não só das condições climáticas (precipitação e evapotranspiração) como também das edáficas (capacidade de campo e ponto de murcha permanente). Estes últimos atributos definem a "capacidade de retenção de água", ou melhor, a "água disponível" e são funções de outras características, tais como: textura, tipo de argilas, teor de matéria orgânica, profundidade efetiva e outras.

$\mathrm{C}$ - Excesso de Água, ou deficiência de oxigênio na zona radicular, é uma função das restrições de drenagem, quer externa (topográfica), quer interna (de 
Tabela 2 - Variáveis paramétricas e efeitos esperados quando se usa a terra; são relações lógicas para auxílio à decisão sobre plantar, ou não plantar, como plantar, com quais condições tecnológicas e manutenção da integridade geo-ambiental das ZRAs. Os graus na última coluna são para os riscos químicos e mecânicos, em função das variáveis paramétricas; os riscos crescem de 1 a 10. O aperfeiçoamento dos indices de risco para diversas bacias é necessário para melhor precisar a avaliação; os sombreados correspondem às definições e condicionantes acima (Org.: Martins Jr. 2007).

\begin{tabular}{|c|c|c|c|c|c|}
\hline \multicolumn{6}{|c|}{ Variáveis Paramétricas para Qualidade da Terra e Efeitos Esperados } \\
\hline Efeitos esperados $\Rightarrow$ & \multirow{2}{*}{$\begin{array}{l}\text { Favo- } \\
\text { rável }\end{array}$} & \multirow{2}{*}{$\begin{array}{c}\text { Desfa- } \\
\text { vorável }\end{array}$} & \multirow{2}{*}{$\begin{array}{l}\text { Faixa fa- } \\
\text { vorável }\end{array}$} & \multirow{2}{*}{ Sensível } & \multirow{2}{*}{$\begin{array}{c}\text { Notas de sensibilidade } \\
\text { de ZRAs e APRs } \\
{[1,10] \mathrm{e}} \\
\mathrm{d}=\text { depende }\end{array}$} \\
\hline Variáveis paramétricas & & & & & \\
\hline \multicolumn{6}{|l|}{ EDÁFICAS } \\
\hline Capacidade de troca de cátions & & & & & 1 \\
\hline Soma de bases trocáveis & & & & & 1 \\
\hline Saturação de bases & & & & & 1 \\
\hline Saturação com alumínio & & & & & 1 \\
\hline Salinidade e/ou alcalinidade & & & & & $7-10$ \\
\hline Matéria orgânica & & & & & $6-10$ \\
\hline Relação C/N & & & & & $6-10$ \\
\hline Fósforo assimilável & & & & & $6-10$ \\
\hline $\mathrm{pH}$ & & & & & $\mathrm{d}$ \\
\hline \multicolumn{6}{|l|}{ CLIMÁTICAS } \\
\hline Precipitação & $1-4$ & $5-8$ & & $9-10$ & $1-4,5-8$ e $9-10$ \\
\hline Evapotranspiração & & & & & $1-3$ \\
\hline Regime pluviométrico & & & & & $3-9$ \\
\hline \multicolumn{6}{|l|}{ TOPOGRÁFICAS } \\
\hline Declividade & $\leq 3$ & $\geq 7$ & 3 a 7 & & $3-7$ \\
\hline Extensão e forma das vertentes & $\leq 2$ & $\geq 8$ & 2 a 8 & & $2-8$ \\
\hline Relevo local & & & & & $2-8$ \\
\hline Risco de inundação & & & & & $1-4$ \\
\hline Cobertura vegetal & & & & & $1-5$ \\
\hline \multicolumn{6}{|c|}{ FORMAÇÕES SUPERFICIAIS } \\
\hline Permeabilidade & & & & & $7-10$ \\
\hline Textura & & & & & $3-9$ \\
\hline Estrutura & & & & & $4-10$ \\
\hline Retenção de água & & & & & $1-3$ \\
\hline Profundidade & & & & & $1-4$ \\
\hline Condições de drenagem & & & & & $3-8$ \\
\hline Textura e tipo de argila & & & & & $4-8$ \\
\hline Pedregosidade e rochosidade & & & & & $4-9$ \\
\hline
\end{tabular}

perfil). Esta limitação é função de três grupos de fatores distintos que se reportam às condições climáticas, topográficas e da permeabilidade e disposição dos estratos no solo - (1) Climáticas: precipitação e evapotranspiração (2) Topográficas: relevo local e risco de inundação e (3) Edáficas: permeabilidade.

D - Susceptibilidade à Erosão - Fator de limitação considerado "agrícola", em contraposição aos anteriores tidos como "ambientais"; define-se como o desgaste potencial da superfície do solo quando submetido a qualquer uso sem práticas especiais de conservação. E função das condições climáticas, topográfi- cas e do próprio solo (edáficas) - (1) climáticas: regime pluviométrico (erosividade), (2) topográficas: relevo e cobertura vegetal e (3) edáficas: textura, estrutura, permeabilidade e retenção de água.

E - Impedimentos à mecanização - (1) topográficos: extensão e forma das vertentes e declividades (2) edáficos: profundidade, condições de drenagem, textura, tipo de argila, pedregosidade e rochosidade.

$\mathrm{Na}$ tabela 2, apresentam-se as variáveis paramétricas, listadas e ordenadas acima, indicando-se os efeitos esperados de cada uma, quando a terra é utilizada. Esses efeitos são distinguidos em: 
(1) Favoráveis - Quando é previsível uma melhoria de produtividade nas terras onde $\mathrm{o}$ atributo possui um valor numérico mensurado ou estimado mais alto,

(2) Desfavoráveis - Comportamento inverso do anterior, ou seja, são de esperar melhores produtividades nas terras onde os valores do atributo são mais baixos,

(3) Faixa Favorável - Existência de um intervalo de valores para os quais se esperam boas respostas, sendo que para aqueles valores do atributo, numericamente superiores ou inferiores, as produtividades esperadas deverão ser reduzidas,

(4) Sensível - Atributo de peso e comportamento diversificado conforme as características de que se reveste. Por exemplo, a textura pode ser de granulometria arenosa ou muito argilosa, o atributo relevo pode ser plano ou montanhoso, tendo ambos, desempenhos bem diferenciados. Contudo, não obedecem a uma escala numérica facilmente mensurável como, por exemplo, o pH ou a capacidade de retenção de água, embora possuam importância e aspectos que não podem deixar de ser assinalados.

Corredores florestais Dadas todas as definições legais, entende-se como corredor florestal (CF): "toda continuidade floral sobre pequenas e/ou grandes extensões ao longo de cursos d'água, ou ao longo de quaisquer partes do território, que permitam a comunicação entre maciços florestais primários, eventualmente remanescentes, ou também plantados, ou também em fase de desenvolvimento secundário". Todo corredor é uma parcela de ecossistemas que permite a troca de genoma tanto para as espécies da flora quanto para espécies animais. Por sua vez "Corredor Florestal EcológicoEconômico" (CFEE) é todo corredor que articula vegetação natural, seja com plantas nativas e/ou exóticas de caráter econômico". Outra característica é a combinação das plantas nativas obedecerem aos aspectos de associações fitossociológicas e fito-ecológicas entre as várias espécies na montagem desses corredores.

Conservação de ZRAs Trata-se da articulação da produção agro-florestal em ZRAs com as quais as necessidades econômicas sejam atendidas nos limites da sustentabilidade geotécnica e da segurança química das recargas dos aqüíferos; ademais essas áreas podem, em maior ou menor grau de modificação, servirem para suportar corredores florestais, os quais, juntos ou não, com agricultura virem a facilitar maior infiltração no aqüífero e maior tempo de duração para o escoamento superficial imediato pós-chuvas, ou ainda menor escoamento com maior infiltração.

QUESTÕES GEO-AMBIENTAIS NO PARACATU Muitas questões ambientais no Vale do Paracatu são predominantemente de escala regional, portanto entre elas a questão das ZRAs. No Projeto CRHA (Martins Jr. et al. 2006) as conclusões sobre as ZRAs, em escala de 1:250.000, são parciais quanto a precisa identificação geográfica da área de infiltração, a não ser pelo fato de que diversas avaliações conduzem esses autores a reverem algumas especificações apresentadas no Plano Diretor do Paracatu (Rural Minas). Questões geológicas como relações entre tipos de rochas / formas / altitudes / densidades de fraturas / atitudes de rochas abrem uma série de questões geo-ambientais, a saber: 1 - quais os tipos de formações superficiais, ou de solos, com ou sem fraturas abertas, e de atributos físicos que caracterizam cada tipo de área de recarga, 2 - quais as condições sensíveis de uma dada ZRA que a torne mais ou menos crítica a intervenções humanas, 3 - quais são as condições geo-ambientais reinantes, se em estado natural, ou em estado de alteração, e/ou mesmo de degradação ambiental e 4 - quais os tipos de atividades antrópicas que são compatíveis com uma dada área, de modo que a segurança ambiental, sendo respeitada, permita uma intervenção economicamente sustentável.

Essas quatro questões são determinantes, em se tratando da caracterização e determinação das condições de segurança ambiental. Dessas condições podemse gerar matrizes de conhecimento que permitam elaborar um sistema de auxílio à decisão com bases em inteligência artificial. As matrizes apresentadas em seqüência (Figs. 2a-2e; Tabs. 3-5) são desenvolvidas pelo método CommonKADS (Schreiber et al. 2000), visando articular conhecimentos interdisciplinares. Devem ser seguidas para compreender-se como se apropria desses vários conhecimentos para decidir sobre projetos de agricultura, de silvicultura e/ou de manejo agro-florestal em áreas sensíveis.

MATRIZES DE CONHECIMENTOS GEO-AGROAMBIENTAIS [Tipos de rochas / geoformas / altitudes / atitudes de rochas / densidades de fraturas / solos / aptidão de solos / parâmetros de aptidão] A matriz é concebida como um conjunto lógico de aspectos que estão, ou podem estar, em relação caso a caso, e cujas conjugações podem implicar em decisões diferentes (Tabs. 3a, 3b).

O conceito de Aptidão de Solos não contempla convenientemente a questão da recarga, dado que qualquer ZRA pode ter solos aptos para diversos tipos de culturas e, no entanto, não ser adequada à agricultura, por outros motivos. A recarga é o fator crítico para a conservação da variação estocástica da circulação da água, isto é das condições de probabilidades condicionais, no tempo cronológico, que regem o funcionamento da atmosfera, medido ao longo de cada ano hidrológico.

Ressalvadas mudanças climáticas notáveis, a quantidade absoluta da água permanece. Varia apenas estocasticamente de ano a ano em função de fatores cíclicos da própria atmosfera e das condições de infiltração e/ou de escoamento superficial imediato pós-chuvas. Em contrapartida, qualquer alteração nas recargas virá, ao longo de algum tempo, afetar a quantidade da disponibilidade de água, especialmente nas estações secas. Esse é o problema ambiental crítico, com efeitos nas atividades agrícolas, eventualmente produzindo quase-desertos, mesmo com quantidade total de água abundante. Esse fato já se observa no vale do São Fran- 


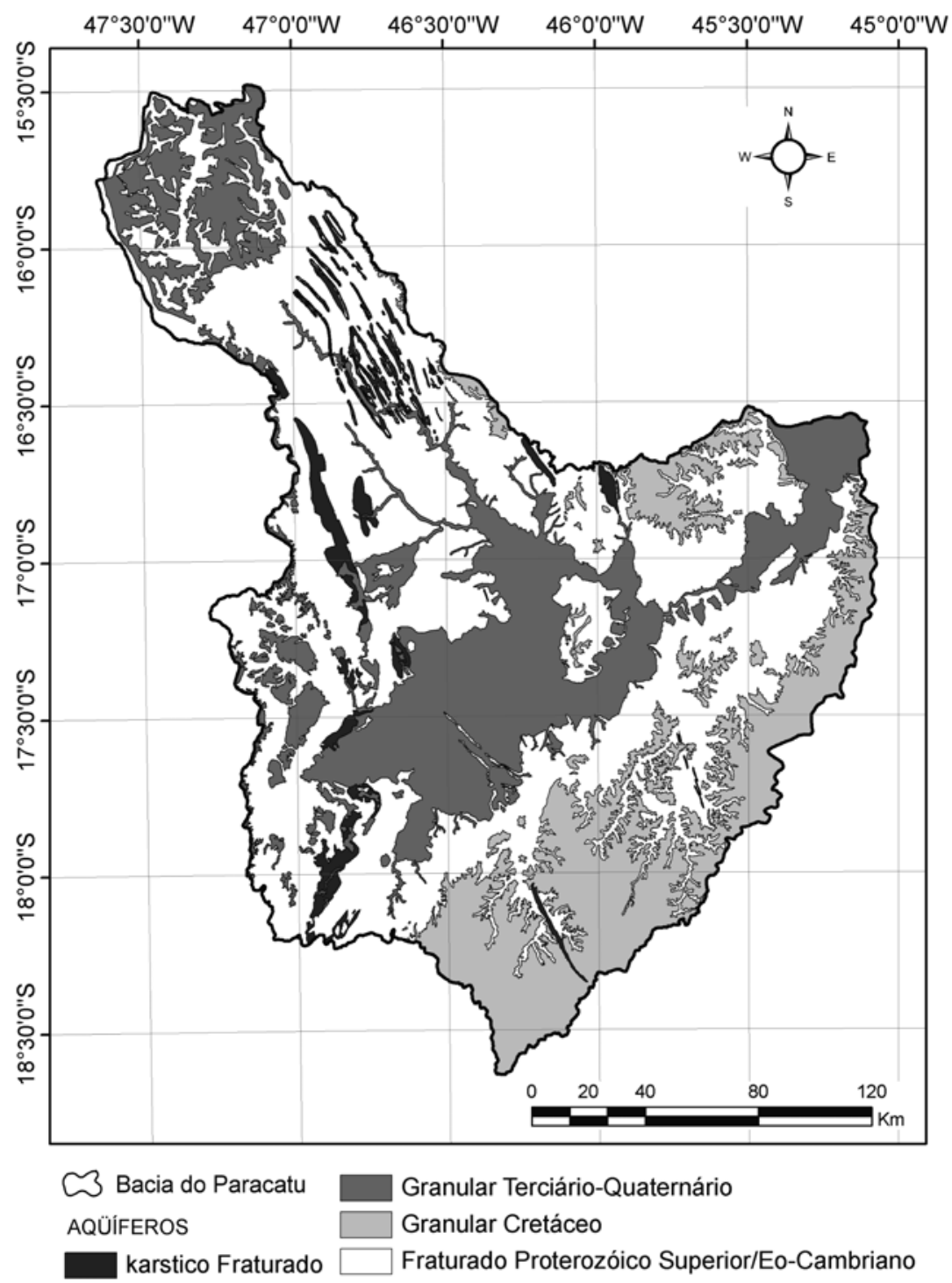

Figura 2 a - Carta dos conjuntos de rochas portadoras de aqüiferos subterrâneos do Vale do Paracatu. Esses são volumes de rochas portadoras, especificos e restritos, com APRs, reservatórios e áreas de exsudação (escala original 1:250.000) (Org.: Martins Jr. 2007).

cisco. O escoamento superficial imediato pós-chuva é o outro fator crítico em áreas de recarga não protegidas, e de solos expostos em qualquer parte da bacia. Escoamento superficial intensivo pós-chuvas em áreas de recarga descobertas implica em menor infiltração. A relação da vegetação com os solos das áreas de recarga, com a infiltração e com os escoamentos superficiais pós-chuvas é a cadeia de fatores a ser devidamente preservada e/ou conservada de modo adequado. A complexidade das situações é previsível nas figuras 2a, 2b, 2c, 2d, 2e. A tabela 4 apresenta uma articulação de conhecimentos em função do conceito e cartografia de Aptidão de solos integrado com condições geotécnicas em ZRAs e APRs. Os enfoques de decisão devem ocorrer para quatro condições - segurança química, segurança do terreno, projetos agro-florestais intensivos, e orgânicos. Na tabela 5 apresenta-se uma estrutura de conhecimentos para uma situação, nada incomum, de agricultura em solos sobre base de rocha granular.

\section{SOLUÇÕES COM INTELIGÊNCIA COMPUTA-}

CIONAL A simulação contextual que se apresenta é uma parte das diversas soluções ligadas ao uso sustentável e conservacionista de ZRAs. Com as formulações que se seguem, apoiadas em parte no método CommonKADS (Schreiber et al., 2000) descrevem-se três Modelos de Organização - MO. Esses recobrem uma parte da visão geral do processo de Modelagem Lógica Integrada vinculada à viabilidade ecológico-econômica de projetos agro-florestais em ZRAs. Os modelos devem ser usados para enunciar injunções: - lógicas, sobre a realidade, sobre problemáticas e questões de implementa- 


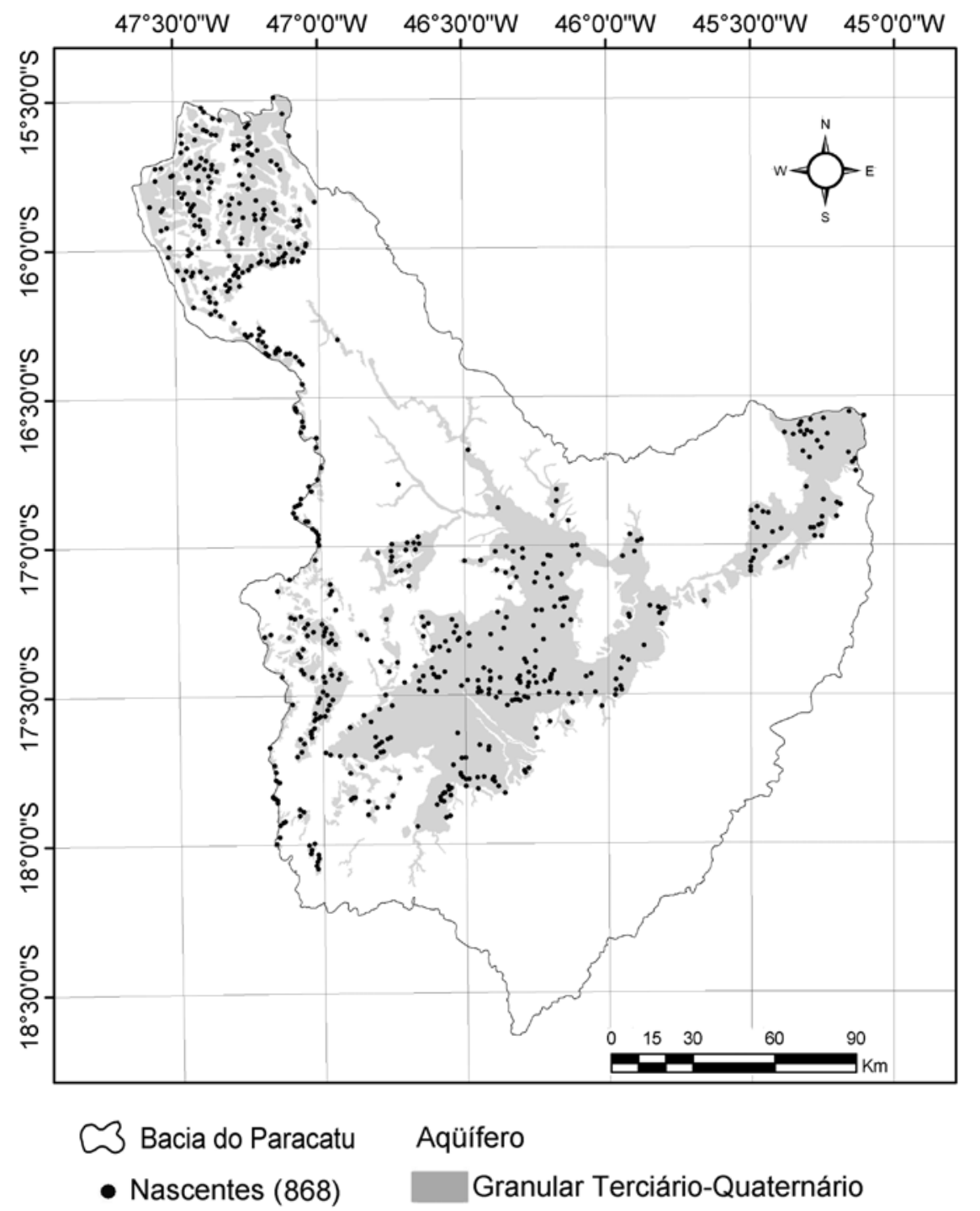

Figura $2 b$ - Essa Zona tida como aqüifero granular Terciário-Quaternário é mais propriamente uma zona de transição da água. As Nascentes ligadas á mesma evidencia a importância hídrica dessa área no Vale (escala original 1:100.000) (Org.: Martins Jr. 2007).

ção do próprio sistema inteligente. A modelagem de uso da terra e da lógica de decisão têm na figura 3 , a caracterização mais básica e contextual das questões lógicas sobre "o que plantar", "onde plantar" e "como plantar".

SOBRE O CONHECIMENTO Um sistema inteligente exige uma qualificação epistemológica do conhecimento, de outro modo não se pode saber o que verdadeiramente se informará. Assim, toda a massa de informações alfa-numéricas, cartográficas, de organogramas, diagramas, fluxogramas e as informações qualitativas devem ser classificadas quanto aos vários estágios cognitivos. Esses estágios são determinados sob os seguintes macro-conceitos: natureza do conhecimento, representado como um intervalo aberto da qualidade e quantidade do conhecimento, que permite os seguintes tipos de classificação epistemológica:
(1) formal rigoroso, no qual se incluem conhecimentos matematizados ou rigorosamente representados sob um paradigma dominante;

(2) empírico quantitativo, o qual informa medidas já feitas, mas sem predição e equações de casos gerais;

(3) heurístico, que pode ser traduzido por métodos adequados de pesquisa que sejam setoriais e nãouniversais, que apresentem soluções boas e permitam uma visão histórica de evolução de conceitos e de suas atualizações;

(4) especializado, quando se tratam de informação baseada em conhecimento inquestionável dentro de uma ciência e, eventualmente, por um paradigma;

(5) baseado em experiência, que é ao mesmo tempo observacional, empírico e heurístico e faz parte da memória de um grupo;

(6) incerto, que pode ser ou não correto, don- 


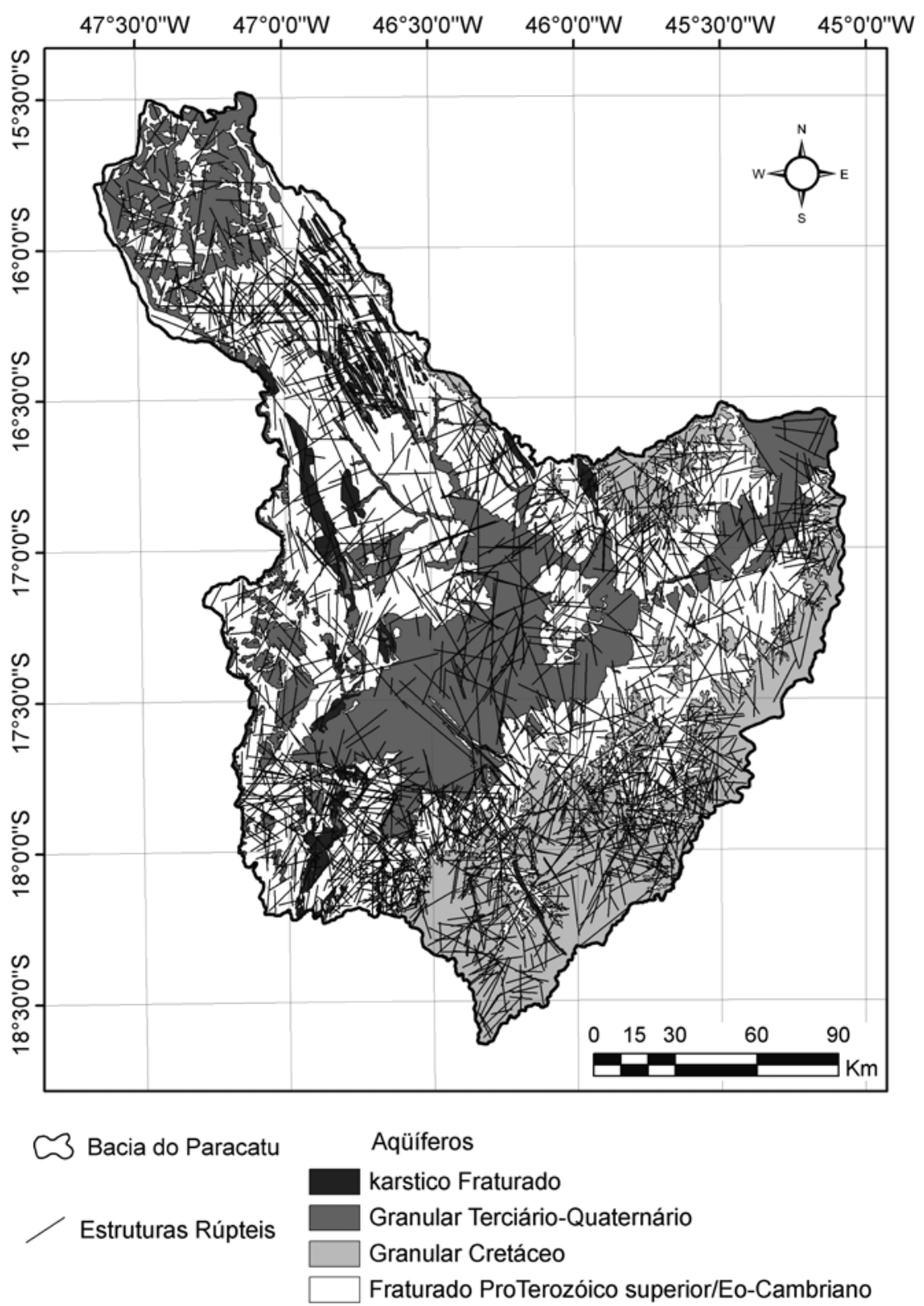

Figura $2 c$ - Conjuntos das rochas portadoras de aqüiferos subterrâneos com o conjunto de estruturas rúpteis, selecionadas para uma densidade própria de representação (escala original 1:250.000) (Org.: Martins Jr. 2007).

de a dúvida deve ser sinalizada bem como a qualidade dessa dúvida;

(7) dificil de se verificar, que pode ser funcional, embora não explicado;

(8) tácito, quando ocorrem acordos não explicitados, mas sabidos entre as partes, e que se pode trabalhar com hipóteses consideradas verossímeis, práticas ou funcionais. A tabela 6 indica a natureza dos diversos conhecimentos científicos.

\section{MODELO DE ORGANIZAÇÃO EM NÍVEL CON- TEXTUAL \\ MO-1 Problemas e oportunidades}

PROBLEMAS (1) Muitos agricultores passam por problemas de degradação de solos e recursos hídricos. (2)
Muitas vezes, nas decisões das atividades humanas em um território, os critérios econômicos (principalmente os de curto prazo), costumam se sobrepor aos critérios ambientais; questões: (1) Perigos químicos: insumos e pesticidas (2) Perigos estruturais: erosão laminar, perda universal de solos, erosão acelerada e perda de nutrientes.

OPORTUNIDADES Oferecer auxílio à decisão geoambiental para agricultores e gestores de bacia hidrográfica, sobre conservação dos solos. Intenciona-se que os usuários passem a assumir uma postura mais coerente em relação as suas atividades de uso territorial, incorporando para decisão as corretas variáveis ambientais, com suas implicações na produtividade econômica. A modelagem permite criar uma articulação da gestão en- 


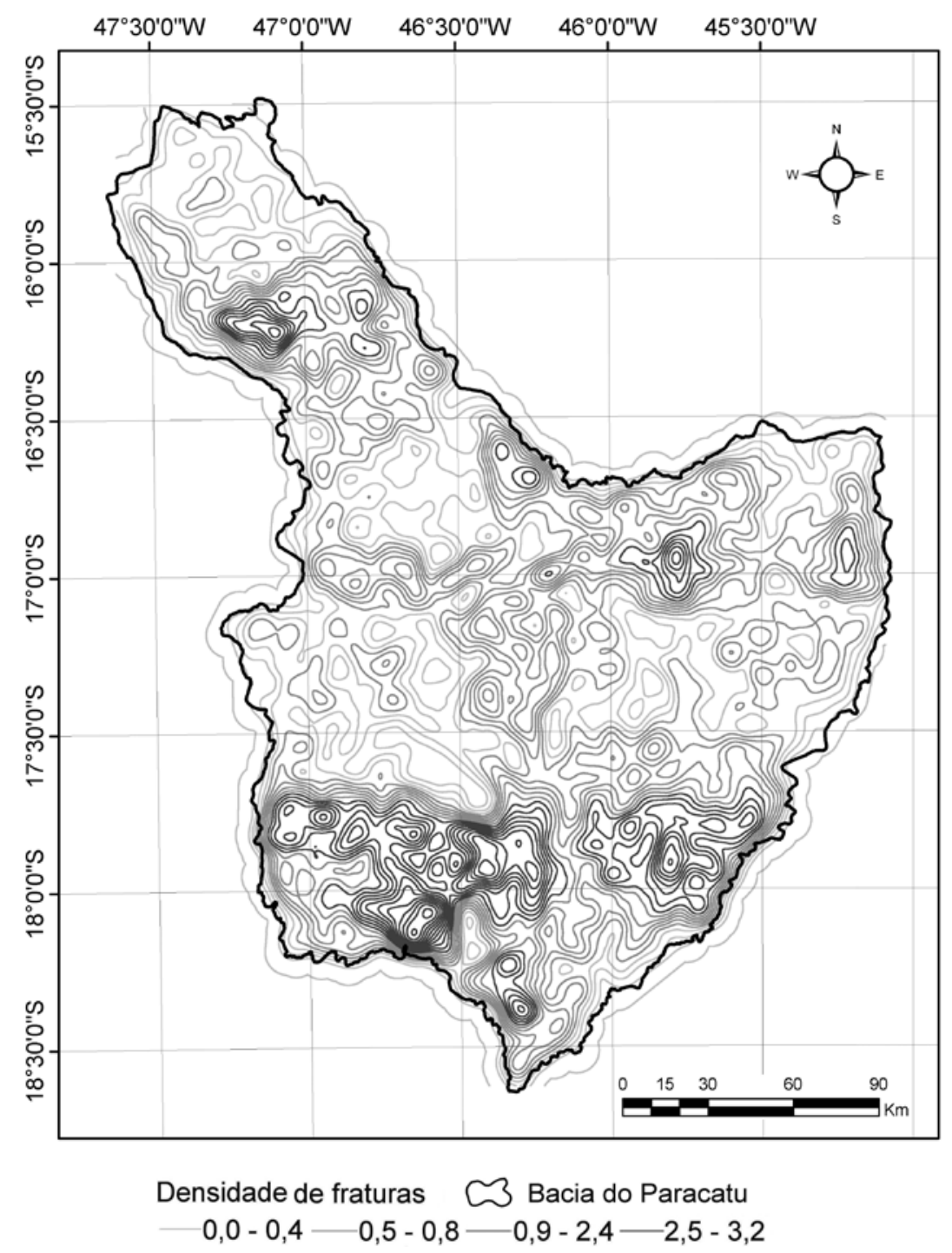

Figura $2 d$ - Conjunto de estruturas rúpteis do Paracatu representadas pelas isolinhas de iguais densidades (escala original 1:250.000) (Org.: Martins Jr. 2007).

tre produtores rurais e gestores de bacia, por integrar os dois modos de planejamento territorial em uma visão de raciocínio ambiental ampla.

Esta modelagem é direcionada a critérios de re-usabilidade e desenvolvimentos posteriores, dando suporte para novas versões de sistemas especialistas de auxílio à decisão em ordenamento territorial, e para desenvolvimento de novos programas especialistas sobre o meio ambiente.

CONTEXTO ORGANIZACIONAL Considera-se os objetivos, os fatores externos e os critérios de sucesso a serem reportados aos objetos "ZRA", ao "mercado agro-econômico', aos "órgãos de decisão" e aos "critérios críticos de conservação" de solos e água, de modo integrado, com uma visão de sustentabilidade.

OBJETIVOS (1) Modelar o conhecimento das Geociências Agrárias e Ambientais, da Agronomia e Silvi- cultura, necessários para a integração do conhecimento de ZRAs à gestão ecológico-econômica do território. (2) Projetar um mecanismo de inferência que utilize esses conhecimentos. (3) Mostrar como e porque as medidas de conservação e preservação de ZRAs podem ser proveitosas economicamente.

FATORES EXTERNOS (1) O mercado Agro-econômico estimula certas culturas e técnicas economicamente viáveis e exclui outras. (2) Incentivos e autorizações governamentais, estimulam práticas agropecuárias, ambientalmente corretas ou não. (3) A existência ou não de órgãos ambientais para fiscalizar, proibir e/ou reorientar as práticas produtivas em um território de ZRAs e APRs não é usual no País. (4) Demandas dos usuários por água subterrânea, para as zonas rural e urbana continuam a ser problema não-resolvido e (5) O clima agravado pelas tendências de mudanças climáticas. 


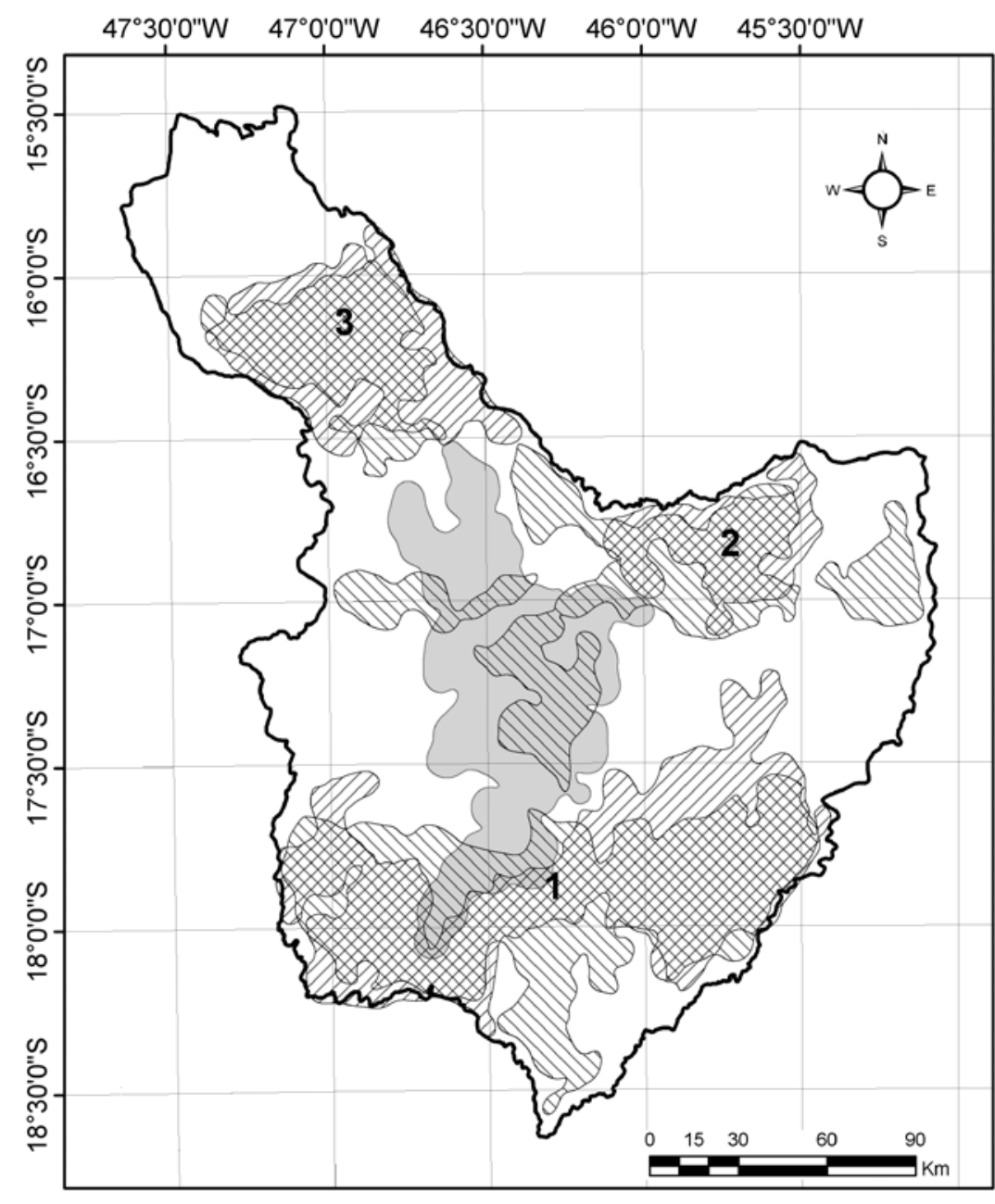

\section{Legenda}

S Bacia do Paracatu

Áreas máximas de:

Densidade de mesofraturas
Densidade de nascentes

Densidade de corpos d'água

Figura 2e - Mapa de áreas de corpos d'água notáveis e aflorantes, de áreas com máxima densidade de meso-fraturas preponderantemente co-incidentes com os máximos de ocorrências de nascentes (áreas 1 a 3); escala original 1:250.000 (Org.: Martins Jr. 2007).

CRITÉRIOS DE SUCESSO (1) Obtenção do aumento ou não-diminuição da infiltração nas ZRAs. (2) Evitar enchentes. (3) Melhorar controle do escoamento superficial imediato pós-chuvas. (4) Manter umidade dos solos locais. (5) Conservação ambiental, com uma política de uso ecológico-econômico. (6) Evitar contaminação química. (7) Evitar a degradação mecânica de solos e rochas.

SOLUÇÕES São as relações de conservação com delimitações do que se fazer, das técnicas eficientes para a produção e a garantia da conservação, agregando-se corredores florestais ecológico-econômicos como novos aspectos ecológicos regionais. De- limita-se assim, como Soluções: (1) estabelecimento de áreas de preservação e/ou conservação prioritárias em ZRAs e como Políticas: (2) preservação em casos ultra-sensíveis e (3) conservação de áreas sensíveis com agricultura e/ou silvicultura. No contexto de ZRAs, que apresentem variáveis paramétricas ambientalmente sensíveis: (4) a delimitação de certas atividades econômicas para esses determinados territórios, (5) a determinação de certas técnicas de conservação de solo e água, a serem incentivadas ou tornadas de uso obrigatório e (6) implementação de corredores ecológico-econômicos nas linhas de cumeada, ou de outras áreas, e em áreas de uso restrito por sobre as ZRAs (Figs. 4 e 5). 
Tabela $3 a$ - Comparação das variáveis de Aptidão de solos e Geotecnia (Org.: Martins Jr. 2007).

\begin{tabular}{|c|c|}
\hline Variáveis Pedológicas Atualizadas para Aptidão Agrícola & Variáveis Geotécnicas* \\
\hline Soma de bases trocáveis (S) & \multirow{6}{*}{ Não têm expressão } \\
\hline Capacidade de troca de cátions $(\mathrm{T})$ & \\
\hline Grau de saturação de bases $(\mathrm{V})$ & \\
\hline Saturação com alumínio & \\
\hline Salinidade** & \\
\hline Alcalinidade** & \\
\hline Matéria orgânica $=\mathrm{C}_{\text {orgânico }} \times 1,724$ & \multirow{3}{*}{ Não têm expressão } \\
\hline Relação Carbono/Nitrogênio & \\
\hline Fósforo assimilável & \\
\hline $\begin{array}{l}\text { Capacidade de retenção de água }=\text { Água }_{1 / 3 a t m} \\
\text { ( ou Equivalente de umidade) ou Capacidade de Campo }\end{array}$ & Capacidade de retenção de água \\
\hline \multirow[t]{2}{*}{ Água disponível } & Teor de umidade atual \\
\hline & Grau de saturação \\
\hline $\begin{array}{l}\text { Condições de drenagem (inferido através da permeabilidade } \\
\text { interna e condições topográficas) }\end{array}$ & Pode-se usar as mesmas variáveis \\
\hline
\end{tabular}

Tabela $3 b$ - continuação. Observações à tabela 3 (3a e 3b):

\begin{tabular}{l|}
\hline Variáveis Pedológicas Atualizadas para Aptidão Agrícola \\
\hline Permeabilidade*** \\
\hline
\end{tabular}

\begin{tabular}{|l}
\multicolumn{1}{c}{ Variáveis Geotécnicas* } \\
\hline Porosidade \\
\hline Permeabilidade \\
\hline Limite de plasticidade \\
\hline Limite de liquidez \\
\hline Índice de plasticidade \\
\hline Índice de consistência \\
\hline Índice de vazios \\
\hline Massa específica natural \\
\hline Massa específica Natural para Sólidos \\
\hline Coesão \\
\hline Ângulo de atrito \\
\hline
\end{tabular}

\begin{tabular}{l|}
\hline Textura \\
\hline \\
\hline Estrutura (inferida a partir do tipo de solo) \\
\hline Tipo de Argila $* * * *$ \\
\hline $\mathrm{pH}$ \\
\hline Pedregosidade (inferida a partir do tipo de solo) \\
\hline Rochosidade (inferida a partir do tipo de solo) \\
\hline Profundidade total (Horizontes A+B+C) \\
\hline Tipo pedológico \\
\hline Aptidão agrícola (Variável Conclusiva)
\end{tabular}

Não têm expressão

\begin{tabular}{|l}
\hline Não tem expressão \\
\hline Pedregosidade \\
\hline Rochosidade \\
\hline Profundidade da Rocha Alterada \\
\hline Tipo de Rocha \\
\hline $\begin{array}{l}\text { Conveniências Geotécnicas } \\
\text { (Variável Conclusiva) }\end{array}$ \\
\hline
\end{tabular}

Observações à Tabela 3 (3a e 3b):

* Aplicáveis a solos (Análise Estrutural de Solos - ASE) e a rochas portadoras de reservatórios de aqüiferos.

** Não constituem problemas na bacia do Paracatu, motivo pelo qual não foram realizados os respectivos testes no Planoroeste II.

*** Quando o terreno é impermeável apresenta problema à agricultura e é inferido por características internas ao perfil (impermes subterrâneos, ou argilas 2:1 em topografia plana ou depressão), e características externas, como topografia de depressões em geral. No Paracatu, devem ser observadas os terrenos de lagoas marginais, planícies fluviais sujeitas a inundação, depressões rasas e solos hidromórficos em geral.

**** Para a Bacia do Paracatu, a predominância é de argilas 1:1, do tipo kaolinita e de óxidos de ferro. 
Lógica para Modelos de Integração de conhecimentos para auxílio à decisão - plantios florestais ecológico-econômicos em zonas de recarga de aqüiferos

Tabela 4 - Articulação das condições de aptidão de solos, geotécnicas e de objetivos agrícolas, florestais e agroflorestais. A manutenção da infiltração em uma ZRA é condição radical do processo de conservação do recurso hídrico na bacia. O sombreado e os espaços em branco indicam as interseções onde ocorrem relações diretas. Essa tabela informa a necessidade da busca das implicações lógicas entre todos os aspectos considerados para cada caso de terreno (Org.: Martins Jr. 2007).

\begin{tabular}{|c|c|c|c|c|c|c|}
\hline \multirow[b]{2}{*}{$\begin{array}{l}\text { Aptidão de } \\
\text { solos }\end{array}$} & \multirow{2}{*}{$\begin{array}{c}\text { Condições das ZRAS } \\
\text { e APRs } \\
\text { recarga com florestas }\end{array}$} & \multirow[b]{2}{*}{$\begin{array}{l}\text { Condições } \\
\text { geotécnicas }\end{array}$} & \multicolumn{4}{|c|}{ Decisão sob enfoque de } \\
\hline & & & $\begin{array}{l}\text { segurança } \\
\text { química }\end{array}$ & $\begin{array}{l}\text { segurança } \\
\text { do terreno }\end{array}$ & $\begin{array}{c}\text { projetos } \\
\text { agroflo-restais } \\
\text { intensivos } \\
\end{array}$ & $\begin{array}{c}\text { projetos } \\
\text { agroflo-restais } \\
\text { orgânicos } \\
\end{array}$ \\
\hline \multirow{12}{*}{ Apto } & \multirow{3}{*}{ favorável } & alta estabilidade & & & & \\
\hline & & vulnerável & & & & \\
\hline & & instável & & & & \\
\hline & \multirow{3}{*}{ indiferente } & alta estabilidade & & & & \\
\hline & & vulnerável & & & & \\
\hline & & instável & & & & \\
\hline & \multirow{3}{*}{ sensível } & alta estabilidade & & & & \\
\hline & & vulnerável & & & & \\
\hline & & instável & & & & \\
\hline & \multirow{3}{*}{ desaconse-lhável } & alta estabilidade & & & & \\
\hline & & vulnerável & & & & \\
\hline & & instável & & & & \\
\hline
\end{tabular}

Tabela 4 - continuação.

\begin{tabular}{|c|c|c|c|c|c|c|}
\hline \multirow[b]{2}{*}{$\begin{array}{l}\text { Aptidão de } \\
\text { solos }\end{array}$} & \multirow[b]{2}{*}{$\begin{array}{l}\text { Favorável em } \\
\text { recarga com florestas }\end{array}$} & \multirow[b]{2}{*}{$\begin{array}{l}\text { Condições } \\
\text { geotécnicas }\end{array}$} & \multicolumn{4}{|c|}{ Decisão sob enfoque de } \\
\hline & & & $\begin{array}{l}\text { segurança } \\
\text { química }\end{array}$ & $\begin{array}{l}\text { segurança do } \\
\text { terreno }\end{array}$ & $\begin{array}{l}\text { projetos } \\
\text { agroflo-restais } \\
\text { intensivos }\end{array}$ & $\begin{array}{c}\text { projetos } \\
\text { agroflo-restais } \\
\text { orgânicos }\end{array}$ \\
\hline \multirow{12}{*}{ Restrito } & \multirow{3}{*}{ favorável } & alta estabilidade & $\mathbb{W U V U U}$ & $\mathbb{Z V H U K ~}$ & & \\
\hline & & vulnerável & & & & \\
\hline & & instável & & & & \\
\hline & \multirow{3}{*}{ indiferente } & alta estabilidade & $2 / 1 / 1$ & $\mathrm{ZHOUV}$ & & \\
\hline & & vulnerável & & & & \\
\hline & & instável & & & & \\
\hline & \multirow{3}{*}{ sensível } & alta estabilidade & & $\mathbb{Z N / K} / /$ & & \\
\hline & & vulnerável & & & & \\
\hline & & instável & & & & \\
\hline & \multirow{3}{*}{ desaconse-lhável } & alta estabilidade & & ZUK KOU & & \\
\hline & & vulnerável & & & & \\
\hline & & instável & & & & \\
\hline \multirow{12}{*}{ Inapto } & \multirow{3}{*}{ favorável } & alta estabilidade & & $\mathrm{ZZZZZZ}$ & & \\
\hline & & vulnerável & & & & \\
\hline & & instável & & & & \\
\hline & \multirow{3}{*}{ indiferente } & alta estabilidade & & $\mathrm{ZUHZUH}$ & & \\
\hline & & vulnerável & & & & \\
\hline & & instável & & & & \\
\hline & \multirow{3}{*}{ sensível } & alta estabilidade & & & & \\
\hline & & vulnerável & & & & \\
\hline & & instável & & & & \\
\hline & \multirow{3}{*}{ desaconse-lhável } & alta estabilidade & & & & \\
\hline & & vulnerável & & & 4 & \\
\hline & & instável & & & $\Leftrightarrow x$ & \\
\hline
\end{tabular}

Significados das achuras. O sinal ? é de condicionalidades a serem ainda exploradas em maior detalhe.

\begin{tabular}{|c|c|c|c|}
\hline \multirow{3}{*}{$\mathrm{Z} / \mathrm{K} / \mathrm{K} / \mathrm{K} / \mathrm{K}$} & Sim, eventualmente condicionado & & Com tecnologia própria \\
\hline & Sim / depende de análise crítica & & \\
\hline & Não & & $\begin{array}{c}\text { Com tecnologia para aptidão e } \\
\text { geotecnia }\end{array}$ \\
\hline & Condicionado a técnicas específicas & & \\
\hline & Sempre favorável & 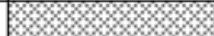 & Com alta tecnologia \\
\hline
\end{tabular}


Tabela 5 - Estudo de caso hipotético para agricultura, silvicultura e zoocultura em rocha granular. As Variáveis selecionadas na coluna Condições paramétricas indicam condições especiais que devem, em nível de detalhe, serem estudadas para estabelecer os Critérios de decisão com os atributos geotécnicos de "alta estabilidade", "vulnerável" e "instável" das Tabelas 2 e 4 com as condições de decisão; assim como para os temas da coluna (Org.: Martins Jr. 2007).

\begin{tabular}{|c|c|c|c|c|c|c|}
\hline \multicolumn{2}{|c|}{ Condições paramétricas } & \multirow[b]{2}{*}{$\begin{array}{l}\text { Condições do } \\
\text { caso-exemplo }\end{array}$} & \multicolumn{3}{|c|}{ Usos } & \multirow{2}{*}{$\begin{array}{c}\text { Critérios de } \\
\text { decisão } \\
\text { favorável, } \\
\text { desaconselhável, } \\
\text { sensível, } \\
\text { indiferente }\end{array}$} \\
\hline $\begin{array}{l}\text { Áreas, sistemas e } \\
\quad \text { ciências }\end{array}$ & Variáveis selecionadas & & agricultura & silvicultura & zoocultura & \\
\hline Zonas de Recarga & $\begin{array}{c}\text { área precisa de recarga } \\
\text { reconhecida }\end{array}$ & ZRA e APR & \multicolumn{3}{|c|}{ ZRA e APR } & depende \\
\hline \multirow{3}{*}{ Lito-estratigrafia } & tipos de rochas & rocha granular & boa no local & idem & idem & sensível a química \\
\hline & $\begin{array}{l}\text { formas do modelado - } \\
\text { geomorfologia }\end{array}$ & $\begin{array}{c}\text { aplainado a baixas } \\
\text { declividades }\end{array}$ & excelente & $\begin{array}{l}\text { em muitas } \\
\text { condições }\end{array}$ & $\begin{array}{l}\text { aplainado e } \\
\text { vertentes }\end{array}$ & $\begin{array}{l}\text { favorável a } \\
\text { sensível }\end{array}$ \\
\hline & $\begin{array}{l}\text { altitude média / } \\
\text { declividade }\end{array}$ & $750 \mathrm{~m} / \mathrm{suave}$ & excelente & $\begin{array}{l}\text { ZRA várias / APR } \\
\text { várias }\end{array}$ & $\begin{array}{l}\text { qualquer/ } \\
\text { suave }\end{array}$ & favorável \\
\hline \multirow{10}{*}{ Geotecnia } & $\begin{array}{c}\text { porosidade solos e/ } \\
\text { ou de formações } \\
\text { superficiais }\end{array}$ & muito alta & exige cuidar & qualquer & $\begin{array}{l}\text { depende de } \\
\text { tecnologia }\end{array}$ & sensível \\
\hline & índice de vazios & muito alto & exige cuidar & varia & idem & sensível \\
\hline & teor de umidade & oscila & oscila & varia & indiferente & indiferente \\
\hline & massa específica natural & indiferente & indiferente & indiferente & indiferente & \\
\hline & grau de saturação & alto & - & - & - & sensível \\
\hline & limite de liquidez & baixo & seguro & produz estabilidade & condicional & desaconselhável \\
\hline & limite de plasticidade & alto & favorece & favorece & condicional & sensível \\
\hline & índice de consistência & baixa & exige cuidar & adequada & condicional & depende da cultura \\
\hline & coesão & boa & - & adequada & - & sensível \\
\hline & ângulo de atrito & inespecífico & - & - & - & \\
\hline Solos & $\begin{array}{l}\text { capacidade de campo } \\
\text { de solos }\end{array}$ & alta & bom para & bom para & indiferente & indiferente \\
\hline \multirow[b]{2}{*}{$\begin{array}{l}\text { Geologia } \\
\text { Estrutural }\end{array}$} & confluência de fraturas & algumas & sensibilidade & indiferente & sensível & sensível \\
\hline & $\begin{array}{l}\text { fraturas paralelas ou } \\
\text { cruzadas }\end{array}$ & várias & sensibilidade & indiferente & sensível & sensível \\
\hline \multirow{3}{*}{ Aptidão Agrícola } & apto & apta & excelente & bom para & condicional & favorável \\
\hline & restrito & exige tecnologia & $\begin{array}{c}\text { exige } \\
\text { tecnologia }\end{array}$ & exige tecnologia & & sensível \\
\hline & inapto & exige tecnologia & $\begin{array}{c}\text { exige } \\
\text { tecnologia }\end{array}$ & exige tecnologia & & sensível \\
\hline \multirow[t]{2}{*}{ Vegetação } & natural (vários tipos) & $\operatorname{sim}$ & conservar & conservar & condicional & $\begin{array}{l}\text { exige cuidados de } \\
\text { conservação }\end{array}$ \\
\hline & plantada & não é o caso & -- & consorciar & condicional & \\
\hline \multicolumn{3}{|c|}{$\begin{array}{l}\text { Critério final de auxílio à decisão, dependendo de tecnologia } \\
\text { eventualmente apropriada }\end{array}$} & \multicolumn{3}{|c|}{ Agricultura com insumos: desaconselhável } & $\begin{array}{l}\text { balanço de todos } \\
\text { os juízos parciais }\end{array}$ \\
\hline
\end{tabular}

MO-2 Aspectos Variantes

SISTEMAS DE INFORMAÇÃO, RECURSOS COMPUTACIONAIS Gerar modelo para INTERNET com servidor-web. O modelo deve interagir com um servidor de sistema de informações geográficas SIGea e com um servidor de um portal de conteúdo científico em Ecologia-Economia - sisORCI, ambos em desenvolvimento (Martins Jr. et al. 2008 b).
TECNOLOGIA, E/OU PATENTES, DIREITOS Com o método CommonKADS e o processo de modelagem do conhecimento em linguagem UML, o núcleo de Inteligência Artificial é programável com sistemas e linguagens livres e de código aberto.

CULTURA Não existe no País uma cultura científica e de gestão para a qual seja previsto o uso de sistemas 


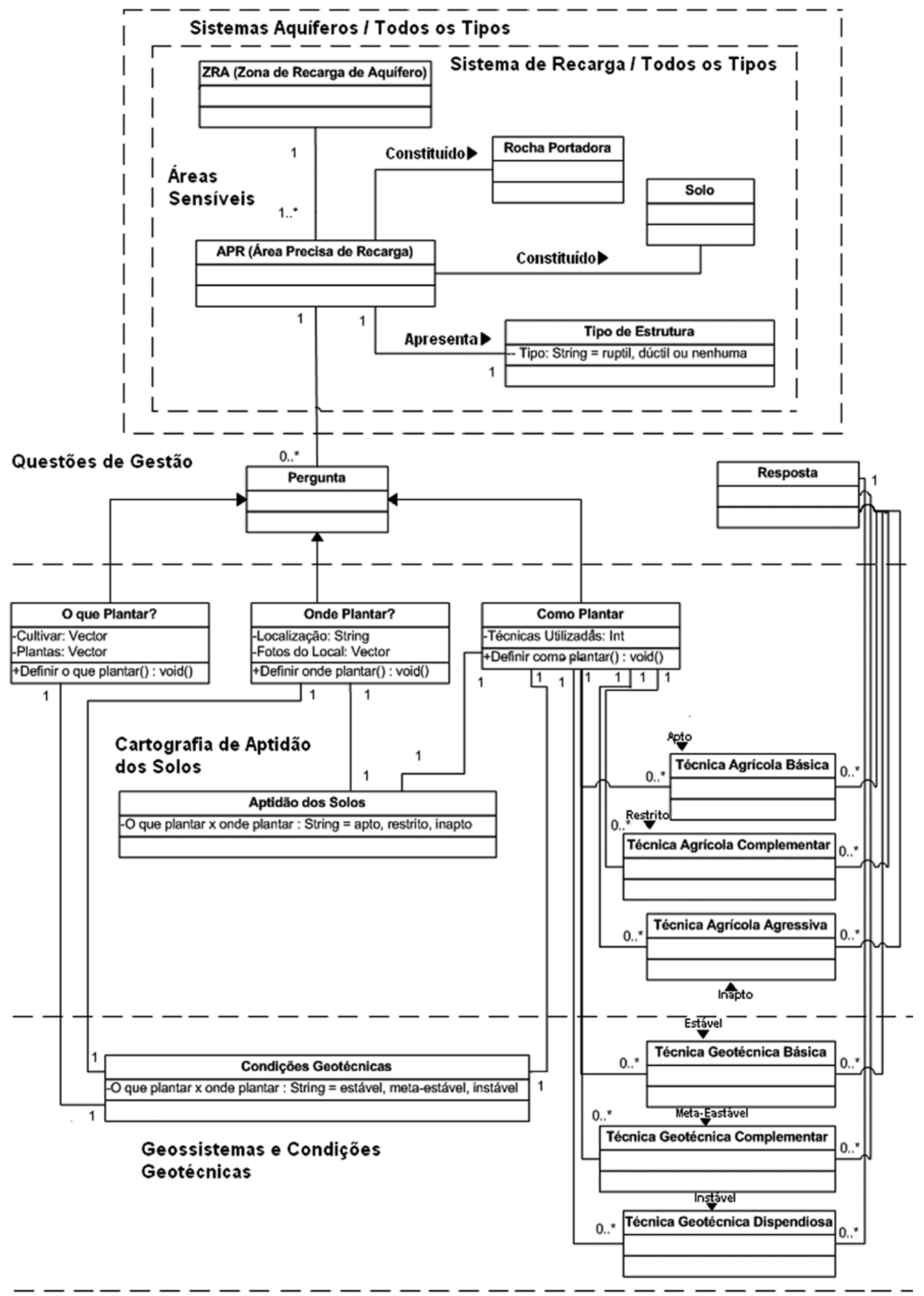

Figura 3 - Questões lógicas sobre uso da terra em ZRAs e APRs para agricultura, silvicultura e projetos agroflorestais. Questões técnicas do "como plantar" devem ser consideradas. Os geosistemas podem estar nas condições estável, meta-estável e instável (Org.: Martins Jr. 2007).

especialistas de modo sistemático. Esse tipo de sistemas oferece novo método para tratar com o meio ambiente e pode ser um começo para a implementação de nova cultura administrativa.

PODER Para implementação das diretivas de gestão de ZRAs e APRs será necessária a utilização dos 
Tabela 6 - Relações comuns de acesso elou oferta de conhecimentos locais no Brasil entre natureza do conhecimento, formas de armazenamento no sistema a ser informatizado, e a disponibilidade e avaliação do conhecimento, em se tratando de conhecimento universal aplicável aos vários casos de bacias e de propriedades rurais. As células sombreadas indicam correlações mais estreitas e as não-sombreadas as menos estreitas (Org.: Martins Jr. 2007).

\begin{tabular}{|c|c|c|c|c|c|c|c|c|c|c|}
\hline \multirow{2}{*}{$\begin{array}{c}\text { Estruturas dos } \\
\text { Conhecimentos } \Downarrow \\
\text { [1] Natureza do } \\
\text { Conhecimento }\end{array}$} & \multicolumn{10}{|c|}{ Temas de Conhecimento } \\
\hline & $\begin{array}{l}\text { Hidro- } \\
\text { geolo-gia }\end{array}$ & $\begin{array}{l}\text { Geologia } \\
\text { Estru- } \\
\text { tural }\end{array}$ & $\begin{array}{l}\text { Estrat- } \\
\text { grafia }\end{array}$ & vege- & $\begin{array}{l}\text { Agrono- } \\
\text { mia }\end{array}$ & $\begin{array}{l}\text { Eng. } \\
\text { Agricola }\end{array}$ & $\begin{array}{l}\text { Hidro- } \\
\text { logia }\end{array}$ & florestal & $\begin{array}{l}\text { Clima- } \\
\text { tologia }\end{array}$ & Pedo- \\
\hline \multicolumn{11}{|l|}{ Formal, rigoroso } \\
\hline \multicolumn{11}{|l|}{ Empírico, quantitativo } \\
\hline \multicolumn{11}{|l|}{$\begin{array}{l}\text { Heuristico: regras de } \\
\text { pesquisa }\end{array}$} \\
\hline \multicolumn{11}{|l|}{$\begin{array}{l}\text { Altamente Especializada } \\
\text { espec. de um domínio }\end{array}$} \\
\hline \multirow{2}{*}{\multicolumn{11}{|c|}{$\begin{array}{l}\text { Baseado em experiência } \\
\text { Imcompleto }\end{array}$}} \\
\hline \multirow{2}{*}{\multicolumn{11}{|c|}{ Imcompleto }} \\
\hline \multirow{2}{*}{\multicolumn{11}{|c|}{$\begin{array}{l}\text { Incerto: pode estar incorreto } \\
\text { Dificil de se verificar }\end{array}$}} \\
\hline & & & & & & & & & & \\
\hline \multicolumn{11}{|l|}{$\begin{array}{l}\text { [2] Formas de } \\
\text { Armazenamento do } \\
\text { conhecimento }\end{array}$} \\
\hline \multicolumn{11}{|l|}{ Mente e/ou tradição } \\
\hline \multicolumn{11}{|l|}{ Papel } \\
\hline \multicolumn{11}{|l|}{ Eletrônico } \\
\hline \multicolumn{11}{|l|}{$\begin{array}{l}\text { [3] Disponibilidade e } \\
\text { Avaliação do } \\
\text { conhecimento }\end{array}$} \\
\hline \multicolumn{11}{|l|}{ Limitações de acesso } \\
\hline \multicolumn{11}{|l|}{ Limitações em qualidade } \\
\hline \multirow{2}{*}{\multicolumn{11}{|c|}{$\begin{array}{l}\text { Limitações na forma } \\
\text { Pode ser melhorado }\end{array}$}} \\
\hline & & & & & & & & & & \\
\hline $\begin{array}{l}\text { Gargalo: limita os outros } \\
\text { conhecimentos }\end{array}$ & & & & & & & & & & \\
\hline
\end{tabular}

Tabela 6 - Continuação

\begin{tabular}{|c|c|c|c|c|}
\hline \multirow{2}{*}{$\begin{array}{c}\text { Estruturas dos } \\
\text { Conhecimentos } \Downarrow \\
\text { [1] Natureza do } \\
\text { Conhecimento }\end{array}$} & \multicolumn{4}{|c|}{ Temas de Conhecimento } \\
\hline & $\begin{array}{l}\text { Aptidâo de } \\
\text { Solos }\end{array}$ & $\begin{array}{l}\text { Gestăo } \\
\text { ambien- } \\
\text { tal }\end{array}$ & $\begin{array}{l}\text { Modelagem } \\
\text { projetos } \\
\text { agricolas }\end{array}$ & $\begin{array}{l}\text { Ordena-mento } \\
\text { do território }\end{array}$ \\
\hline \multicolumn{5}{|l|}{ Formal, rigoroso } \\
\hline \multicolumn{5}{|l|}{ Empírico, quantitativo } \\
\hline \multicolumn{5}{|l|}{$\begin{array}{l}\text { Heurístico: regras de } \\
\text { pesquisa }\end{array}$} \\
\hline \multicolumn{5}{|l|}{$\begin{array}{l}\text { Altamente Especializada } \\
\text { espec. de um dominio }\end{array}$} \\
\hline \multirow{2}{*}{\multicolumn{5}{|c|}{ Baseado em experiência }} \\
\hline \multirow{2}{*}{\multicolumn{2}{|c|}{ Imcompleto }} & & & \\
\hline \multicolumn{4}{|c|}{ Incerto: pode estar incorreto } & \\
\hline \multicolumn{5}{|c|}{ Dificil de se verificar } \\
\hline \multicolumn{5}{|l|}{$\begin{array}{l}\text { [2] Formas de } \\
\text { Armazenamento do } \\
\text { conhecimento }\end{array}$} \\
\hline \multicolumn{5}{|l|}{ Mente e/ou tradição } \\
\hline \multicolumn{5}{|l|}{ Papel } \\
\hline \multicolumn{5}{|l|}{ Eletrônico } \\
\hline \multicolumn{5}{|l|}{$\begin{array}{l}\text { [3] Disponibilidade e } \\
\text { Avaliação do } \\
\text { conhecimento }\end{array}$} \\
\hline \multicolumn{5}{|l|}{ Limitações de acesso } \\
\hline \multicolumn{5}{|l|}{ Limitações em qualidade } \\
\hline \multicolumn{5}{|l|}{ Limitações na forma } \\
\hline \multicolumn{5}{|l|}{ Pode ser melhorado } \\
\hline $\begin{array}{l}\text { Gargalo: limita os outros } \\
\text { conhecimentos }\end{array}$ & & & & \\
\hline
\end{tabular}

instrumentos administrativos e legais de preservação e conservação ambiental instituídos pelo Governo. Incluem-se os órgãos ambientais, a Política Nacional de
Recursos Hídricos e a legislação ambiental aplicável. A cultura atualmente existente no campo e na administração pública, bem como no Poder Público em seus 


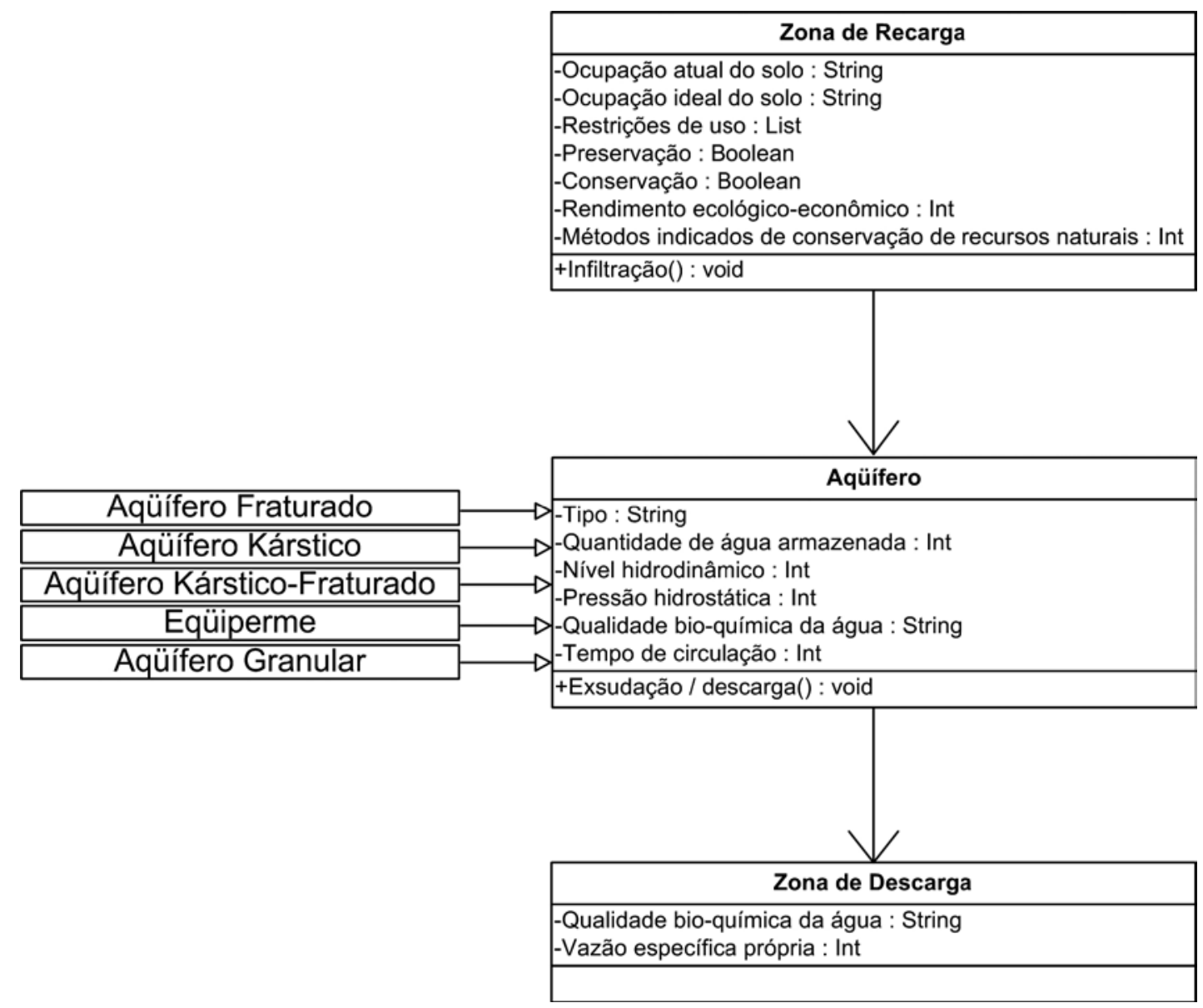

Figura 4 - Diagrama de classes em nivel de contexto em UML; são indicados os objetos geológicos (ZRAs, reservatórios de aqüiferos e zonas de descarga). Processos naturais elou induzidos podem alterar as taxas de trocas de energia e massa. Os métodos de segurança (conservação, ocupação ideal, restrições de uso, rendimentos, métodos de conservação) são programáveis. Símbolos: int - informação numérica; string - informação textual; boolean - informação lógica; void - informações variantes no tempo; list - lista de variáveis (Org.: Martins Jr. 2007).

aspectos constituídos e aplicados indicam as possibilidades de efetiva aplicação do sistema de IA para o auxílio à decisão.

MO-3 Viabilidade de Execução A viabilidade envolve as questões financeiras, técnicas, social e ambiental bem como a modelagem dessas condições que determina um dos fatores de corte para que a decisão seja positiva ou negativa.

BENEFÍCIOS ECONOAMICOS Os benefícios do planejamento territorial são vários e refletem-se dentro da cadeia de processos geo-ecológicos e econômicos. Citam-se: (1) eventuais melhoras na regularidade da vazão hídrica a médios e longos prazos, que resultam em melhores condições para o desenvolvimento da economia agropecuária; (2) melhor uso consuntivo do recurso hídrico; (3) diversos ganhos de produtividade, devido às melhorias ambientais que atuam em diversos segmentos do processo agrícola. É complexo estimar, a priori, o valor agregadas, principalmente estimativas em longo prazo.

CUSTOS ESPERADOS Técnicas agrícolas e de conservação de solos e águas envolvem custos de implementação e manutenção a serem modelados, e a modelagem parte dos princípios de gestão ambiental propostos.

CONHECIMENTO ARMAZENADO E PROCESSO DE RACIOCÍNIO As variáveis do conhecimento estão lançadas nas tabelas 3 a 5 e figuras $2 \mathrm{a}$ a $2 \mathrm{e}$. A partir de então é possível criar formulações lógicas para determinar se as condições do ambiente são favoráveis, indiferentes, sensíveis ou desfavoráveis, quanto a ocupação agrícola e florestal, tendo em vista a manutenção do ciclo hidrológico e a viabilidade ecológico-econômica.

INTERAÇÃO COM O USUÁRIO FINAL Deve ser amigável e interativo entre o usuário e o prestador de serviços. O usuário será informado sobre as questões 
ORGANOGRAMA de CONTEXTO das PESQUISAS para ESTABELECIMENTO das RELAÇÕES LÓGICAS

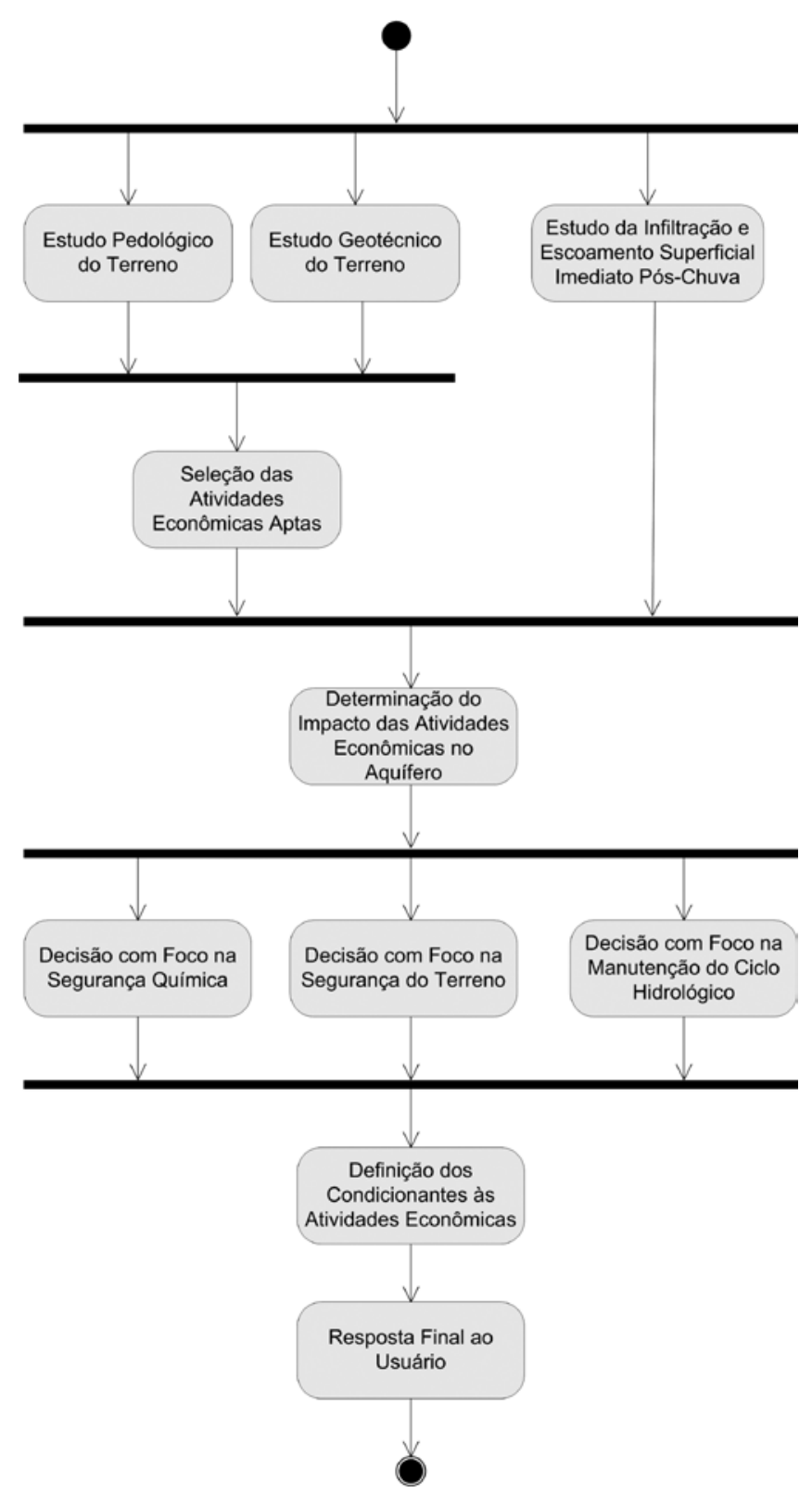

USUÁRIOS

Figura 5 - Diagrama de Atividades em nivel de contexto para pesquisas. Consideram-se, para auxílio à decisão as condições limites (área de preservação, área de conservação, segurança química, métodos obrigatórios de segurança geotécnica, compatibilidades recíprocas e incompatibilidades entre os vários parâmetros) (Org.: Martins Jr. 2007). geo-ecológicas e econômicas envolvidas em determinado uso do território, portando-se o sistema como um instrumento de suporte à gestão, assim como de educação ambiental.

RISCOS E INCERTEZAS Ressalta-se a possibilidade de eventual auxílio à decisão sobre base informacional ainda incompleta.

RISCOS E INCERTEZAS DE IMPLEMENTAÇÃO Os problemas sociológicos da zona rural devem ser trabalhados pelos serviços de extensão rural, que poderão estar em parceria com a equipe mantenedora do modelo especialista; os centros produtores de conhecimentos e de tecnologia devem atender à demanda de conhecimentos, condição essencial para o sucesso de uso e aplicação do programa.

RESULTADOS, CUSTOS E BENEFÍCIOS ESPERADOS Espera-se que os estudos das Geociências Agrárias e Ambientais para as ZRAs, aliados à gestão ambiental e à metodologia de Arquitetura de Conhecimentos (Martins Jr. et al. 2008 b) possam esclarecer sobre os aqüíferos e sobre os procedimentos ótimos de ocupação territorial, para melhor rendimento ecológico-econômico e conservação dos recursos hídricos.

CONCLUSÕES Fica evidente que o desenvolvimento de sistemas inteligentes é um passo maior para a implementação das Geociências Agrárias e Ambientais - GAA. A questão lógica é um dos passos mais importantes para desenvolver a aplicabilidade das Geociências, e nesse sentido essa aplicabilidade deve ser entendida no âmbito interdisciplinar. As ZRAs devem e podem ser utilizadas de modo conseqüente com a conservação de solos e da circulação da água, em especial da infiltração, embora isto em um primeiro tempo possa parecer contrário ao espírito da lei. Todavia, o uso agrícola e silvicultural em ZRAs no País é generalizado e muito comum no Paracatu. A Aptidão de solos, Geotecnia, Geologia estrutural são necessários, em cada caso, para se estabelecer o que é universal e as particularidades de cada situação em ZRAs para, desse modo, gerar uma nova cultura de gestão ambiental e agrícola de bacias hidrográficas. Ficaram estabelecidos diversos passos lógicos fundamentais das GAA para se prosseguir com a implementação de um sistema inteligente de auxílio à decisão.

Agradecimentos Estudos e desenvolvimento financiado pela FAPEMIG-Fundação de Amparo a Pesquisa do Estado de Minas Gerais e MCT/FINEP/Fundo Setorial CT-Hidro.

\section{Referências}

Beek K.J. 1978. Land evaluation for agicultural development. Wageningen International Institute for Land Reclamation and Improvement, 333p. (publi- cation 23).

Beek K.J. \& Bennema J. 1972. Land evaluation for agricultural land use planning; an ecological method- 
ology. Dept. Soil Sci. And Geol., Agric.University, Wageningen. Ed. em espanhol: Boletim Latinoamericano sobre Fomento de Tierras y Águas 3. Projeto Regional FAO/PNUD-RLA 70/457, Santiago do Chile.

CETEC. 1981. $2^{\circ}$ Plano de Desenvolvimento Integrado do Noroeste Mineiro: Recursos Naturais. Belo Horizonte. Série de Publicações Técnicas 2, 16 mapas.

Ginsberg M. 1993. Essentials of Artificial Inteligence Morgan Kaufmann Publihsers - USA.

Lepsch I.F., Bellinazzi Jr. R., Bertolini D., Espíndola C.R. 1983. Manual para levantamento utilitário do meio físico e classificação de terras no sistema de capacidade de uso. Campinas: SBCS, 175p.

Martins Jr. P.P. 1998. Fundamentos Conceituais para o Desenvolvimento e a Prática das Geociências Agrárias e Ambientais. A Terra em Revista. $\mathrm{n}^{\circ}$. 4, Outubro, p. 10-15.

Martins Jr. P.P. 2000. Epistemologia Fundamental. Um Estudo Introdutório sobre a Estrutura do Conhecimento e a Aplicação Prática da Epistemologia na Pesquisa Científica. Belo Horizonte: Relatório Final. Memória Técnica do CETEC. 169 p.

Martins Jr. P.P. 2003. As proposições Metodológicas do Projeto CRHA. Belo Horizonte: Nota Técnica NT-CRHA-01. 39p. Memória Técnica do CETEC. CETEC, UFOP. Projeto financiado MCT/FINEP 2.132/2002. Disponível: www.cetec.br/crha

Martins Jr. P.P., Pereira M.A.S., Novaes L.A.d'A., Vasconcelos V.V. 2005. Zonas de Recarga de Aqüiferos - Questões Estruturais e Geo-ambientais. Belo Horizonte: Fundação CETEC (Memória Técnica) / UFOP-EM-DEGEO. Nota Técnica NT-CRHA 52. 19p. Disponível: www.crha.cetec.br

Martins Jr. P.P., Pereira M.A.S., Novaes L.A.d'A., Vasconcelos V.V. 2005. Zonas de Recarga de Aqü̈iferos - Reservatórios - Nascentes - Questões Geo-Ambientais. Belo Horizonte: Nota Técnica NT-CRHA 54/2005. Memória Técnica do CETEC. Fundação CETEC, UFOP, IGA. Disponível: www.cetec.br/ crha

Martins Jr. P.P. (coord.), Carneiro J.A., Endo I., Fernandes, M.M., Marques A.F.S.M., Vasconcelos V.V., Diniz C.P.L., Novaes L.A.d'A., Tolentino, J.A., Moura L.C., Pereira M.A.S., Rosa S.A. 2006. Conservação de Recurso Hídrico no Âmbito da Gestão Ambiental e Agrícola de Bacia Hidrográfica. Belo Horizonte e Ouro Preto: Projeto CRHA (2003-2006). Memória Técnica do CETEC. Fundação CETEC, UFOP, IGAM. Financiamento MCT / FINEP / Fundo Setorial CT-Hidro 2002. Relatórios Finais. Cartografia. Disponível: www.cetec.br/crha

Martins Jr. P.P., Endo, I., Carneiro J.A., Novaes L.A.d'A., Pereira M.A.S., Vasconcelos V.V. 2006. Modelo de Integração de Conhecimentos Geológicos para Auxílio à Decisão sobre Uso da Terra em Zonas de Recarga de Aqüíferos. Revista Brasileira de Geociências, 36(4):651-662.

Martins Jr. P.P. (Coord.), Pereira J.S., Abreu Jr. J.C., Diniz C.P.L., Paiva D.A. 2008 a. Arquitetura de Conhecimentos em Ecologia-economia para Gestão Ambiental de Bacia Hidrográfica. Belo Horizonte: Projeto ACEE (2005-2008). Memória Técnica do CETEC. Financiamento CNPq Edital 14-2004 Inovação Tecnológica. Relatório Final. 273 p. Disponível: www.cetec.br/sisorci

Martins Jr. P.P., Carneiro J.A., Novaes L.A.d'A., Vasconcelos V.V., Moura L.C., Andrade L.M.G., Paiva D.A. 2008 b. Modelagem Geo-ambiental e Interdisciplinar para Ordenamento do Território com Corredores Florestais Ecológico-econômicos. Fortaleza: Revista de Geologia, 21(1):79-97.

Ramalho Filho A. \& Beek K.J. 1995. Sistema de Avaliação da Aptidão Agrícola das Terras. $3^{\mathrm{a}}$ edição revista, Rio de Janeiro. SUPLAN-EMBRAPA/SNLCS, $65 \mathrm{p}$.

RURAL MINAS. 1996. Plano Diretor de Recursos Hidricos do Vale do Paracatu. Disponível em: <http:// www.abrh.org.br/novo/ii_simp_rec_hidric_centro_ oeste_campo_grande28.pdf $>$. Ácesso em: 25 fev. 2007

Schreiber G., Akkermans H., Anjewierden A., De Hoog R., Shadbolt N., Van De Velde W., Wielinga B. 2000. Knowledge Engineering and Management. The CommonKADS Methodology. London: The MIT Press. 447 p.

Manuscrito ID 13814 Submetido em 02 de abril de 2009 Aceito em 26 de fevereiro de 2010 